\title{
Mixing Processes in High-Level Waste Tanks
}

\author{
Per F. Peterson \\ Associate Professor \\ Department of Nuclear Engineering \\ University of California, Berkeley \\ Berkeley, CA 94720-1730
}

DOE/EM Contract: FDDE-FG07-96ER14731-09/99

Progress Report For the Period:

Sept. 15, 1996 - Sept. 14, 1997

to:

Dr. Oscar P. Manley

Engineering Research Program

Office of Basic Energy Sciences

U.S. Department of Energy

Germantown, MD 20874

Dr. Ramoncity Massey

Office of Science and Technology

Office of Environmental Management

U.S. Department of Energy, EM-52

1000 Independence Avenue, Room 5A-031

Washington D.C. 20585 


\section{Table of Contents}

1. Introduction .......................................................................

2. Experimental Program Status ........................................................... 4

3. Modeling Program Status .............................................................. 5

4. Conclusions for Progress in 96 - '97 ................................................. 7

5.References ........................................................................ 8

Appendix A Mixing Processes by Natural Convection Flow through two Openings ........9

Appendix B Results of Benchmark Test Results ..................................... 33 


\section{Introduction}

U.C. Berkeley has made excellent progress in the last year in building and running experiments and performing analysis to study mixing processes that can affect the distribution of fuel and oxygen in the air space of DOE high-level waste tanks, and the potential to create flammable concentrations at isolated locations, achieving all of the milestones outlined in our proposal. The DOE support has allowed the acquisition of key experimental equipment, and has funded the full-time efforts of one doctoral student and one postdoctoral researcher working on the project. In addition, one masters student and one other doctoral student, funded by external sources, have also contributed to our research effort.

Flammable gases can be generated in DOE high-level waste tanks, including radiolytic hydrogen, and during cesium precipitation from salt solutions, benzene. Under normal operating conditions the potential for deflagration or detonation from these gases is precluded by purging and ventilation systems, which remove the flammable gases and maintain a well-mixed condition in the tanks. Upon failure of the ventilation system, due to seismic or other events, however, it has proven more difficult to make strong arguments for well-mixed conditions, due to the potential for density-induced stratification which can potentially sequester fuel or oxidizer at concentrations significantly higher than average. This has complicated the task of defining the safety basis for tank operation.

We are currently developing numerical tools for modeling the transient evolution of fuel and oxygen concentrations in waste tanks following loss of ventilation. When used with reasonable grid resolutions, standard multi-dimensional fluid dynamics codes suffer from excessive numerical diffusion effects, which strongly over predict mixing and provide nonconservative estimates, particularly after stratification occurs. The National Institute of Standards and Technology (NIST) has developed useful codes for predicting stratification and mixing due to fires in enclosures, but these codes are not supported by appropriate experiments for waste tanks, and do not consider mixing induced by injected jets, or the detailed distribution of fuel and oxygen concentration.

The UCB Thermal Hydraulics Group model BMIX (Berkeley Mechanistic Mixing Model) is being developed to mechanistically predict mixing processes in large waste-tank volumes, where mixing processes can be driven by hot and cold vertical and horizontal surfaces and injected buoyant jets. We are supporting the model with scaled experiments using water/salt solutions, as well as separate experiments using air with simulant fuels (helium and refrigerant-22 for hydrogen and benzene) to study the specific mixing processes which occur in waste tanks, and will also support the implementation of the code for use in waste tank operations. This year's experimental efforts have focused on scaled water systems to study the exchange flows which occur through tank ceiling openings following loss of ventilation, as well the mixing processes that occur below the ceiling. These water experiments are providing data and insight for our modeling effort while construction of our larger air/benzene simulant experiment is underway. 


\section{Experimental Program Status}

Our mixing experiments have two primary components: a series of experiments conducted in Plexiglas tanks studying scaled mixing processes in water and water/salt or water/sugar systems, and larger scale experiments using air with freon as a benzene simulant and helium as a hydrogen simulant. Substantial progress was made in conducting the water experiments during the past year. The Masters degree report that resulted from this work is appended to this progress report (Appendix A). Progress was also made in the construction of the air experiment, and experimental results are expected to be generated during the upcoming year.

The water experiments completed this year have addressed two issues of importance to waste tank operations. The first involved the study of exchange flows through perforated horizontal partitions. Such exchange flows, driven by buoyancy and fluctuating external pressure, are the primary mechanism bringing ambient air into waste tanks through the many openings in the tank cover, following loss of ventilation. For Tank 48 at SRP, where cesium precipitation takes place, such exchange flows are the mechanism that would provide oxygen into the nitrogen-inerted tank space. Our experiments, described in the appendix, provided fundamental information for modeling exchange flow rates into the tank vapor space.

These experiments also allowed us to simulate the evolution of the vertical density and composition distribution in a stratified volume. The primary question here is how a dense, buoyant plume of air would mix upon entering a tank from the ceiling, and how much dilution would occur before the plume reached the tank liquid, where fuel concentrations would be the highest. The water system provided a useful analog for this process. In addition to employing standard techniques to measure the velocity of the jets entering the bottom volume of the experiment (hot film anemometry) and to visualize the buoyant jets (ink), we developed a new experimental method to measure the vertical density distribution directly, using the deflection of a sheet laser to measure the vertical distribution of the index of refraction, as described in greater detail in the Appendix A. Test results for several sugar water and salt water experiments are reported in Appendix B.

Progress continues on the construction of the air experiment, with all of the major components and instruments procured and construction underway. As described in the proposal, this experiment will allow the study of mixing processes under scaled conditions more closely matching waste tank conditions. 


\section{Modeling Program Status}

Mixing and 'transport in large waste-tank volumes is controlled by the multidimensional equations describing mass, momentum and energy conservation, and by boundary conditions imposed at walls, structures, and fluid inlets and outlets. For large enclosures, careful scaling arguments show that mixing is generated by free buoyant jets arising from the injection of fluid or buoyancy into the enclosure, and by temperature and/or concentration gradients generated near surfaces by heat and mass transfer at walls, cooling tubes, and liquid-vapor interfaces. For large enclosures like waste-tank air spaces, scaling shows that these free and wall jets are generally turbulent and are generally relatively thin.

When one attempts to numerically solve the multi-dimensional mass, momentum, and energy equations with CFD codes, very fine grid resolution is required to resolve these thin jet structures, yet such fine grid resolution is difficult or impossible to provide due to computational expense. However, we have shown that the ambient fluid between jets tends to organize into either a homogeneously mixed condition or a vertically stratified condition that can be described by a one-dimensional temperature and concentration distribution. Furthermore, we can predict the transition between the well-mixed and stratified conditions [1,2]. This allows us to describe mixing processes in large, complex enclosures using one-dimensional differential equations, with transport in free and wall jets modeled using standard integral techniques. With this goal in mind, we are constructing a simple, computationally efficient numerical tool which can be used predicting the transient evolution of fuel and oxygen concentrations in DOE high-level waste tanks following loss of ventilation.

The present model is constructed using a Lagrangian formulation of the conservation of mass, momentum and energy. In the Lagrangian formulation the enclosure is firstly divided into a number of Control Volumes (CVs) and the conservation equations are then written down for each of the CVs. The conservation of either mass, momentum or energy consists of a sum of the rate of change of the conserved quantity, internal generation and fluxes through the Control Volumes surfaces (CSs). Assuming that fluid within the enclosure consists of I components (or species), there are (I+1) conservation equations for each CV. Transport of matter and internal energy between the CVs are governed by two phenomena. Firstly transport is due to entrainment from various plumes of both forced (i.e. purge jet) and natural convection type (i.e. leakage flow) and secondly to diffusion of mass and heat for exchange between neighboring CVs. The present model assumes incompressibility and can handle general cases with I components (species) and $\mathrm{P}$ plumes. If fluid is injected into the tank, the same volume of fluid must be removed (since we are assuming incompressibility) and this is done by allowing one sink to be placed anywhere in the enclosure. The combined model consists of $(\mathrm{I}+\mathrm{l}) \mathrm{K}$ coupled partial differential equations (PDEs) to be solved, where $\mathrm{K}$ is the number of control volumes. In order to solve the PDEs they are discretized in both time and space using standard explicit 1st order approximations of the derivatives. In the discretization procedure for the diffusive processes special attention is given to the possible discontinuities of the physical properties such that the discretization error is minimized. Stability of this scheme is assured if the time step is small enough that the volumes of the CVs stay positive. Therefore, it is expected that it is accuracy requirements and not the stability which will dictate the maximum permissable time step. In addition, the Lagrangian modeling is excellent for preserving large discontinuities since numerical diffusion is nonexistent (or at least fully controllable by the user) in this formulation. The numerical model is relatively simple in the incompressible case and we, therefore, decided to implement the model in Matlab and 
not, for instance, $\mathrm{C}++$. In Matlab it is easy to upgrade and alter the model since code development is very fast as soon as the main skeleton of the implementation is constructed. Furthermore, another positive feature of Matlab is that it facilitates easy pre- and postprocessing of data. At this time most of the coding is accomplished so during the coming months the code will be finished. Following the code development the code and mathematical model will be benchmarked and verified through a comparison with the experimental data discussed in the previous section. 


\section{Conclusions for Progress in 996 - 99}

Our work is on track to meet the task schedule from our original proposal. We now have experimental data for benchmarking our modeling method from water experiments, and will have air data during the next year. We have developed a useful new technique to measure concentration distributions in water systems, allowing us to measure in detail the transient vertical distribution of concentration that occurs due to exchange flows from a perforated ceiling into a large volume. This will ultimately allow us to provide improved calculations for the mixing of oxygen entering an inerted waste tank following loss of ventilation. 


\section{References}

1. P.F. Peterson, "Scaling and Analysis of Mixing in Large, Stratified Volumes," International Journal Of Heat and Mass Transfer, Vol. 37, Suppl. 1, pp. 97-106, 1994.

2. E. Hihara and P.F. Peterson, "Mixing in Thermally Stratified Fluid Volumes by Buoyant Jets," submitted to the ASME-JSME Joint Thermal Engineering Conference, March, 1995. 


\title{
Appendix A
}

\section{Mixing Processes by Natural Convection Flow Through two Openings in Horizontal Partition in Enclosed Tank}

\author{
by \\ Choonjoo Lee \\ Master's Project Report .
}

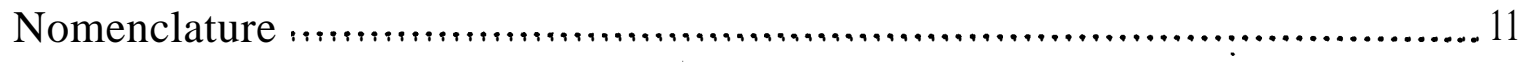

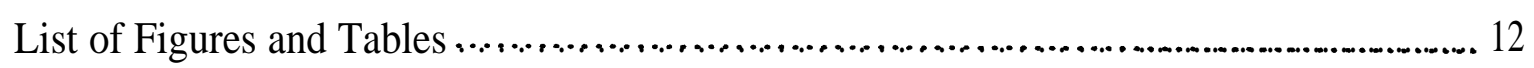

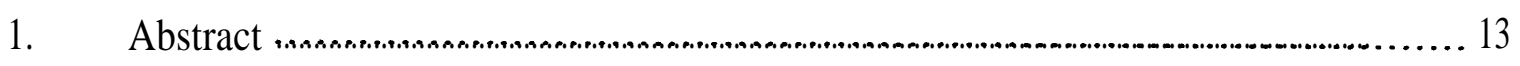

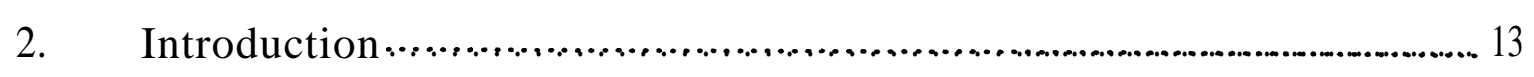

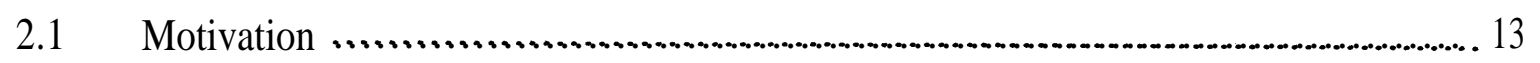

2.2 Problems Considered

2.3 Literature Reviews

2.3.1 Studies on Flow Pattern 14

2.3.2 Studies on Buoyant Jet Flow ….............................................................................. 18

3. Experimental Investigation

3.1. Experimental Arrangement.................................................................. 18

3.2 Experimental Procedure (.............................................................20

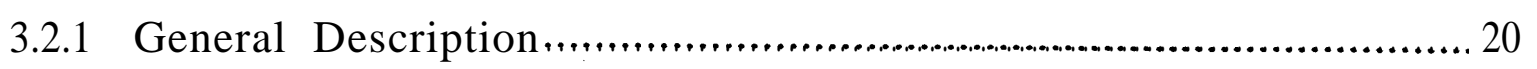

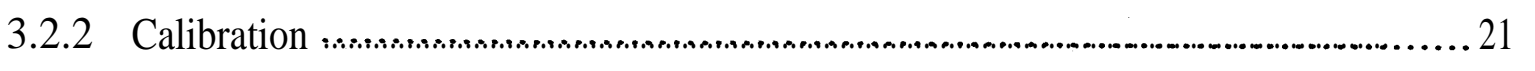

3.2.2.1 Hot Film Probe .........................................................................21

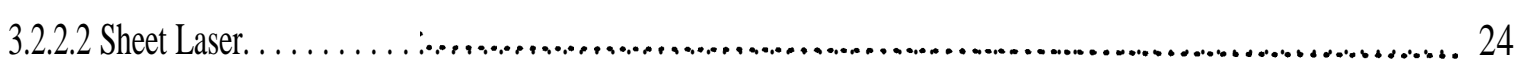

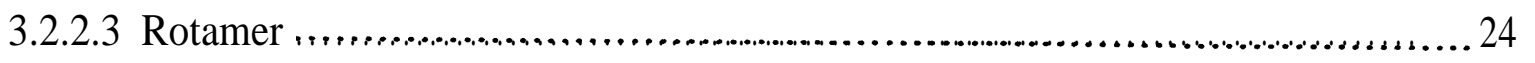

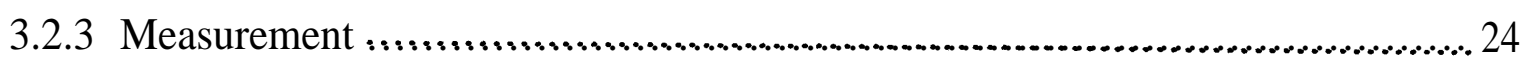




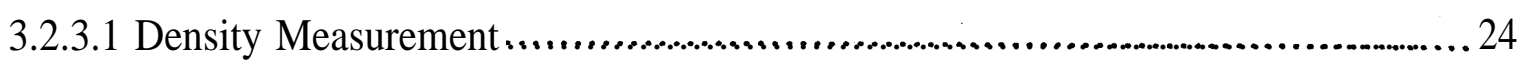

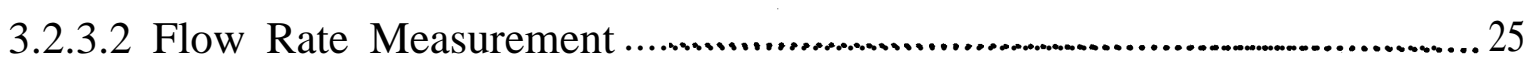

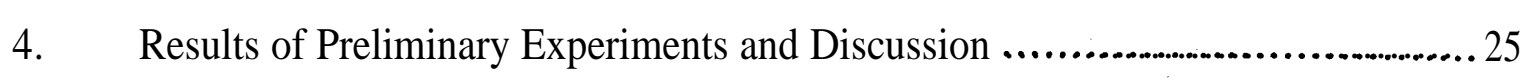

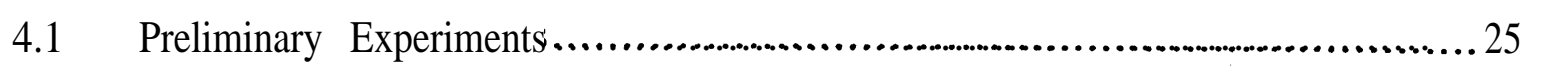

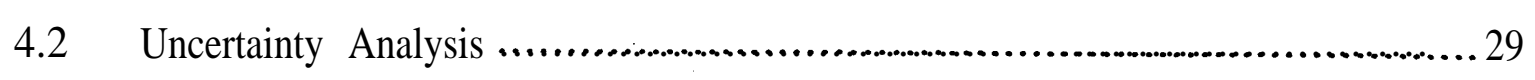

5. Conclusion and Future Works …............................................................2

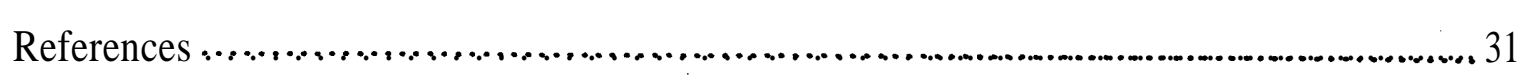




\section{Nomenclature}

$A_{\text {vent }}=$ cross-sectional area of vent

$\mathrm{D}=$ vent diameter

$\delta=$ partition thickness

$\Delta \rho=$ difference between top and bottom compartment densities

$g=$ acceleration of gravity

$\mathrm{L}=$ vent length

$L / D=$ vent opening length to diameter ratio

$\mathrm{P}_{\mathrm{BOT}}=$ pressure below the vented partition

$P_{\text {rot }}=$ pressure above the vented partition

$\operatorname{Pr}=\frac{\mu C_{p}}{k}=\frac{v}{\alpha}$ Diffusion of momentum/diffusion of heat

$\mathrm{Q}=$ exchange volumetric flow rate

$\mathrm{Q}_{\mathrm{BF}}=$ buoyancy-driven component of combined convection

$Q_{c c}=$ purely buoyancy-driven exchange flow rate across a opening

$Q_{u}=$ one-way buoyancy-driven or supply flow rate

$\operatorname{Re}=\frac{\rho V L}{\mu}=\frac{V L}{v}$ Inertia Force/Viscous Force

Sc $=\frac{\mu}{\rho D_{c}}=\frac{v}{D_{c}}$ Diffusion of momentum/diffusion of mass

$\rho$ = density

$\bar{\rho}=$ arithmetic average of the top and bottom compartment densities

$\rho_{t}=$ asymptotic limit for the density in either compartment when the density difference would become zero as time $\rightarrow \infty$

$t$ = time measured from the beginning of experiments

$\mathrm{V}=$ volume of a compartment

W/D $=$ Partition Width to Vent Diameter Ratio

\section{subscripts}

$\Delta=$ scale for normalization

$\mathrm{f}=$ final value

$\mathrm{H}=$ related to the top compartment

$\mathrm{H}, \mathrm{O}=$ initial value, related to the top compartment

$\mathrm{L}=$ related to the bottom compartment

$\mathrm{L}, \mathrm{O}=$ initial value, related to the bottom compartment 


\section{LIST OF FIGURES}

Figure

PAGE

1 Schematic of horizontal partition

2 Schematic of two-opening configuration

3 Illustration of observed flow configurations

4 Density-driven countercurrent and one way flow between sealed compartments connected by two openings

5 Measured exchange rates across a horizontal partition with two openings

6 Experimental facility

7 Schematic showing method of measuring tank vertical density distribution with laser-light sheet using changing index of refraction

8 Calibration curve

9 Schematic of probe and anemometer Wheatstone Bridge

10 Rotameter calibration curve

11 Flow patterns of $\mathrm{L} / \mathrm{D}=0.0313$

12 Flow patterns of $\mathrm{L} / \mathrm{D}=0.0835,0.333$, and 3.149

13 Measured flow rate with $\Delta \rho=60\left[\mathrm{~kg} / \mathrm{m}^{3}\right]$

14 The stability of a hot-film probe in water

15 Video image of mixing process for $\mathrm{L} / \mathrm{D}=3.149$

\section{LIST OF TABLES}

Table 1 Initial Flow rate data 


\section{Abstract}

An experimental investigation has been carried out on the unidirectional exchange flow through two openings through a horizontal partition in a tank. A plexiglass tank with a horizontal partition in the middle was constructed to simulate the exchange flow due to the unstable system configuration, by filling the upper and lower compartment with sugar water and pure water, respectively. Experiments have been carried out on the natural convection flow that occurs after removing two plugs. The upper liquid is dyed, and the flow types in the range of $0.0313<\mathrm{L} / \mathrm{D}<3.145$ were recorded on $\mathrm{S}-\mathrm{VHS}$ tapes and analyzed later. The flow rates through the openings for $\mathrm{L} / \mathrm{D}=3.145$ were measured by a hot film probe(HFP) connected to a DANTEC data acquisition system. Also the density was measured for the whole vertical range of test section by light deflection technique and those data was used to retrieve the right flow rate data from hot film probe measurements, which means that the flow rate corresponding to flow density is chosen because hot film probe is sensitive to the flow density fluctuation.

\section{Introduction}

\subsection{Motivation}

This experiment was started from basic questions about instability. But the results of this experiment can be used or give some useful information in various fields of interest:

- predict the stratification phenomena and the mixing processes in waste storage tanks when the ventilation system is disabled.

- modeling of exchange flows in compartment fires, when the molecular viscosity and thermal diffusivity are not important parameters, K.D. Steckler, H.R. Baum and J.G. Quintiere( 1986) verified that the brine vs. water model is appropriate for modeling of fire induced flows in multiroom enclosures.

- improve the understanding of the mixing processes that occur in reactor containment.

- verify modeling of plume entrainment and the density distribution generated in the ambient fluid around the plume.

\subsection{The problems considered}

The flow patterns, mixing and stratification phenomena in an enclosed tank with a horizontal partition(See Fig.1) have been investigated experimentally. Purely density driven flows were induced by a gravitationally unstable system configuration, that is, a heavier fluid located above a lighter fluid. The possible variables that may govern the flow patterns have been tested to see the influences such as the opening length to diameter ratio $\mathrm{L} / \mathrm{D}$, the number of openings, the partition width to opening diameter ratio W/D and density difference across the opening. Many experiments showed the strong tendency for stratification to occur for even small density differences. The light deflection technique was used to measure the density of ambient fluid. The density information at the inlet of chimney provides the right place to choose the appropriate flow rate conversion data from a calibration table. In addition, density data shows how the fluid stratifies. 

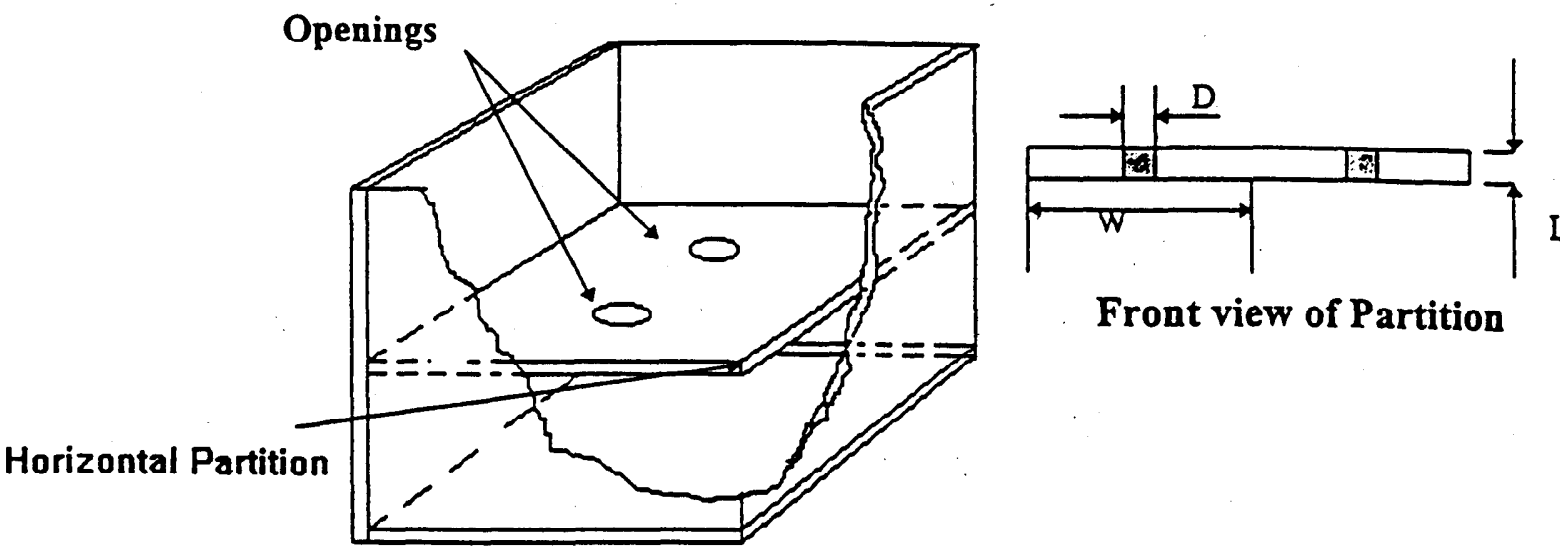

Front view of Partition

Fig.1 Schematic of Horizontal Partition

\subsection{Literature Review}

\subsubsection{Studies on Flow Patterns}

T.A.Conover et al. (1995) well summarized previous works. Much research has been done in the general area of natural convection in enclosures (i.e., Gebhart et al., 1988; Jaluria and Cooper, 1989). Brown and Solvason( 1962) and Brown( 1962) were among the first to study natural convection through openings in vertical and horizontal partitions between enclosures. Air was used as the working fluid. Their studies covered a range of 0.0825 to 0.75 for the L/D ratio of openings. Fire- induced flow through openings in vertical walls of an enclosure was first studied and documented by Prahl and Emmons(1975). Mathematical models of the flow have been proposed by Steckler et al.(1982,1984) and Emmons (1988). Flow contraction and head losses at the openings were modeled through the use of a flow coefficient by invoking Bernoulli's equation. The effects of variable density, turbulence, viscosity, and thermal diffusion were neglected. Steckler et al. (1984) did not find any dependence of the measured flow coefficient on fire strength, opening geometry, and fire location. Steckler et al. (1986) gave theoretical justification for using brine/water analog for studying fire-induced flows in enclosures. In this configuration, hot and cold air were replaced by fresh water and brine solution, respectively. When viscous and heat transfer effects are small, steckler et al. (1986) showed that analogy between the two flow configurations existed provided that Reynolds number based on vent height and velocity of the buoyant fluid, and the vent aspect ratio were the same, and the Prandtl number for air in the fire-induced flow was the same as the Schmidt number for brine in water for the brine/water analog.

The brine/water analog to study buoyancy flows through vents between enclosures has been used by several researchers. Epstein(1988) and Conover and Kumar(1993) have used the analog to study the special case where the externally applied pressure across the vent is zero. Tan and Jaluria (1992) and Jaluria et al. (1993) have studied cases where the vent flow is governed by both pressure and density differential across the vent. The effects of 
pressure differential has also been reported by Heskestad and Spaulding( 1991) and Cooper( 1994).

Only Epstein( 1988) and Epstein and Kenton( 1989) extended the work from a single opening to multiple openings. They observed three different flow configurations involving both one-way and countercurrent flows within the openings. The geometric configuration of the openings is shown in Fig.2. The openings were separated by a distance of approximately $0.15 \mathrm{~m}$. The effect of the spacing between openings was not explored in his study, since it is likely to be small. The observed flow patterns are shown in Fig.3. It is apparent from this study and from closely related work reported in the literature that the flow within any opening of a multiple opening system may be bidirectional if the unidirectional flow established throughout the system is not high enough to arrest the opposing flow in the opening. In other words, some minimum unidirectional, "purging" or "flooding" velocity is required to prevent countercurrent flow within the opening. In the flow configuration shown in Fig.3(a) the strength of the unidirectional convective loop is sufficient to prevent the downward flow of heavier liquid into opening 2. In the situation depicted in Fig. 3(b), however, the loop flow is not strong enough to oppose the downward movement of heavier fluid at opening 1 . In some cases the unidirectional convective loop may be too weak to prevent bidirectional flow at both openings(Fig. 3( c )).

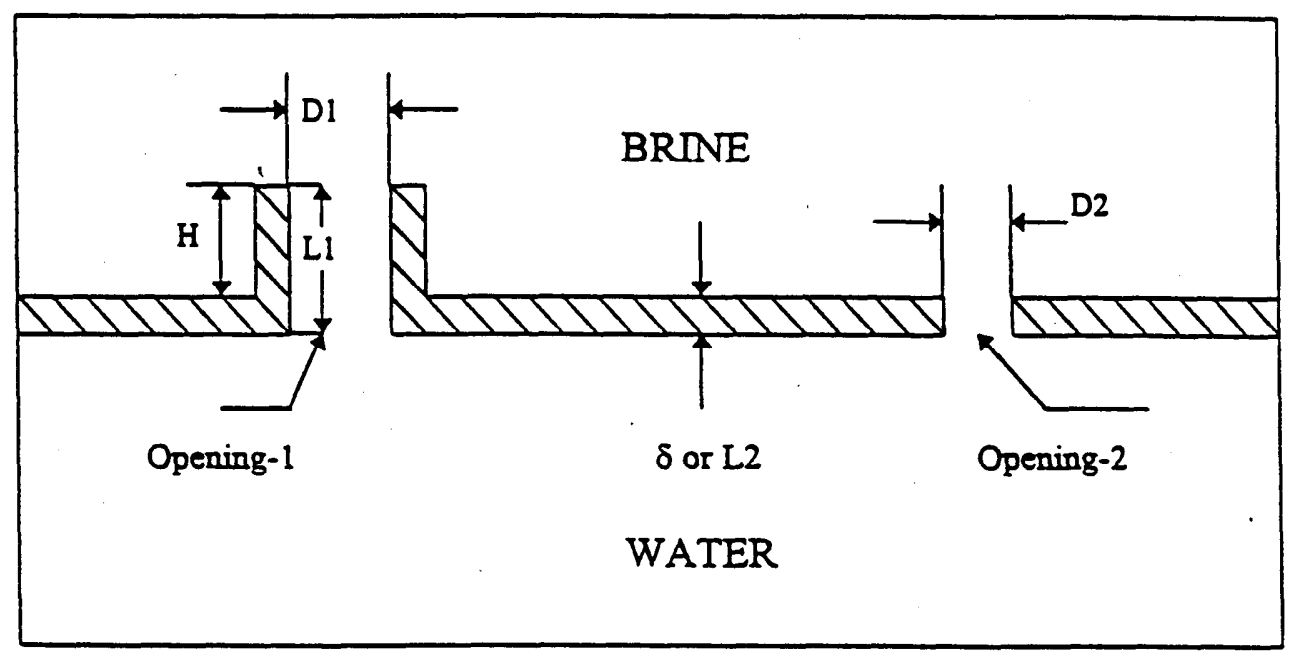

Fig.2 Schematic of two-opening configuration(Fig.4 of Epstein,1 988)

An expression for the exchange flow rate for the one-way flow configuration illustrated in Fig.3(a) can be obtained by application of the Bernoulli equation.

For upward unidirectional flow through opening 1, we have

$$
P_{L}-P_{H, 1}=\frac{1}{2} \rho_{L} U_{1}^{2}+\frac{K_{1}}{2} \rho_{L} U_{1}^{2}+\rho_{L} g(H+\delta)
$$

where $P_{L}$ is the pressure beneath the openings, $P_{\mathrm{H}, 1}$ is the pressure above opening $1, U_{1}$ is the fluid velocity within opening 1 , and $K_{1}$ is the loss coefficient for the entrance flow into opening 1 . The first term on the right hand side of the above equation is the loss due to the reentrant flow from opening 1. 


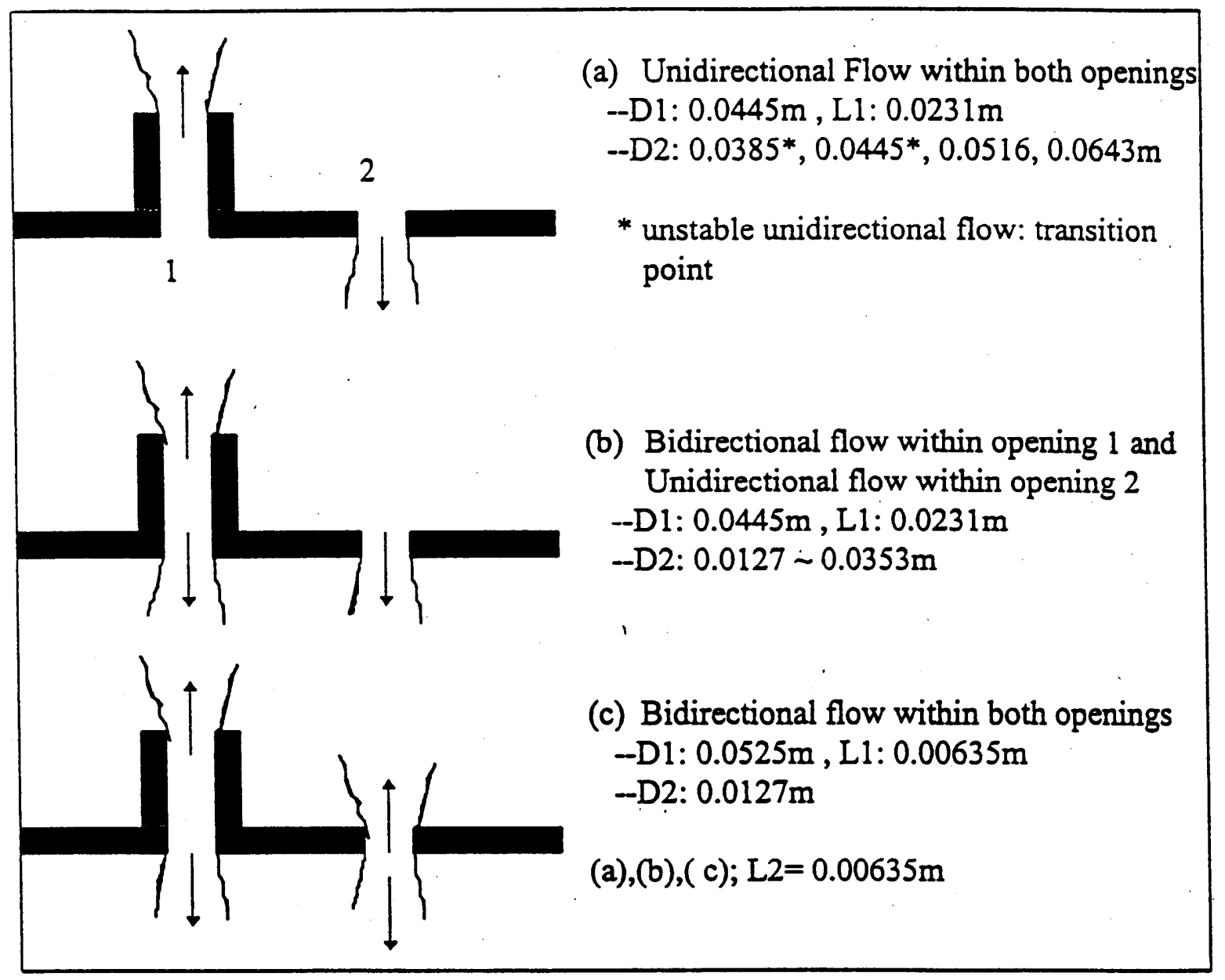

Fig.3 Illustration of observed flow configurations with the two opening system

( Fig.5 and Table 3 of Epstein,1988).

The Bernoulli equation applied to opening 2 gives

$$
P_{H .2}-P_{L}=\frac{1}{2} \rho_{H} U_{2}^{2}+\frac{K_{2}}{2} \rho_{H} U_{2}^{2}-\rho_{H} g \delta
$$

where $P_{H, 2}$ is the pressure above opening $2, U_{2}$ is the downward directed velocity within opening 2 , and $\mathbf{K}_{\mathbf{2}}$ is the loss coefficient for the entrance flow into opening 2 .

The vertical pressure difference in the upper fluid is

$$
\mathrm{P}_{\mathrm{H}, 2}-\mathrm{P}_{\mathrm{H}, 1}=\rho_{\mathrm{H}} \mathrm{gH}
$$

Substitution of equations (1) and (2) into (3) results in

$$
\frac{1}{2} \rho_{L}\left(1+K_{1}\right) U_{1}^{2}+\frac{1}{2} \rho_{H}\left(1+K_{2}\right) U_{2}^{2}=\left(\rho_{H}-\rho_{L}\right) g L_{1}
$$

Assuming no net volumetric flow to each compartment, the unidirectional flow $\operatorname{rate}\left(\mathrm{Q}_{\mathrm{u}}\right)$ is given as

$$
Q_{u}=A_{1} U_{1}=A_{2} U_{2}
$$

Assuming that the entrance flow loss coefficients for openings 1 and 2 are the same and are equal to 0.78 , equation (4) becomes 


$$
Q_{U}=1.06\left[\frac{A_{1}^{2} g \Delta \rho L_{1}}{\rho_{L}+\rho_{H}\left(\frac{A_{1}}{A_{2}}\right)^{2}}\right]^{0.5}
$$

Comparing this equation with experimental results, the final corrected form of equation (6) is obtained by replacing the coefficient 1.06 with 0.805 .

Epstein and Kenton(1989) obtained the dimensionless correlation form of the critical flow rate $\mathrm{q}$ above which the heavier fluid is prevented from entering opening 1 , with a relative error to experiment data of less than about 20 percent,

$$
\frac{q}{\left(D^{5} g \Delta \rho / \bar{\rho}\right)^{1 / 2}}=\frac{0.19\left[1+4 \times 10^{3}(\mathrm{~L} / \mathrm{D})^{3}\right]^{1 / 9}}{\left(1+5.091 \times 10^{-2}(\mathrm{~L} / \mathrm{D})^{16 / 7}\left[1+4 \times 10^{3}(\mathrm{~L} / \mathrm{D})^{3}\right]^{4 / 9}\right)^{1 / 4}}
$$

The net exchange flow rate through two openings between compartments, namely $\mathrm{Q}$ is formulated extending the work of a correlation for combined flow through a single opening as (refer to Fig.4)

$$
Q_{=}=Q_{u}+Q_{B F}=Q_{u}+Q_{c c}\left(1-Q_{J} / q\right)^{2.3}
$$

where $\mathbf{Q}_{\mathbf{u}}=$ one way buoyancy-driven or supply flow rate,

$Q_{c c}=$ purely buoyancy-driven exchange flow rate across an opening,

$\mathbf{q}=$ flooding or purging flow rate, respectively.

Equation (8) is plotted with measured exchange rates $\mathrm{Q}$ for the experiments involving two openings and the flow pattern shown in Fig.4.

Fig. 5 shows that the exchange rates fall consistently on a straight line. So, the combined flow problems involving more than two openings and two compartments can be treated with equation (8).

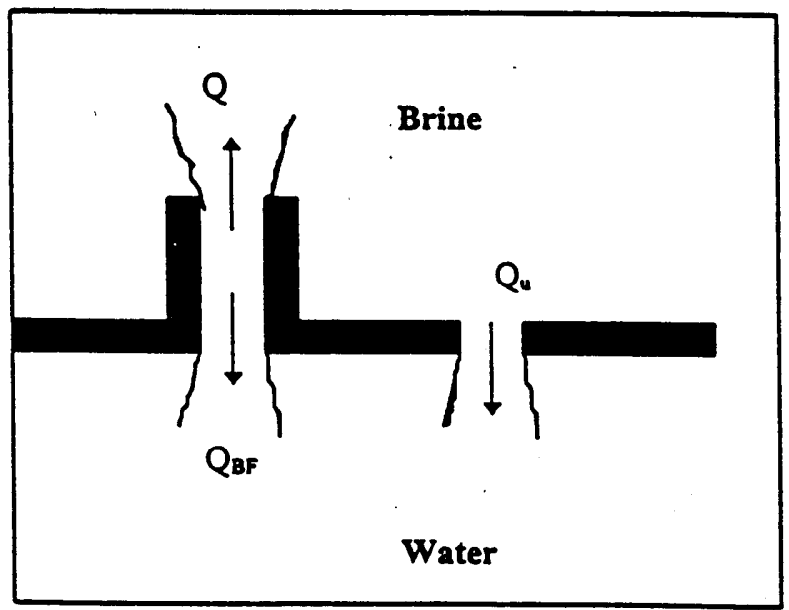

Fig. 4 Density-driven countercurrent and one-way flow between sealed compartments connected by two openings (Fig.6 of Epstein and Kenton, 1989) 


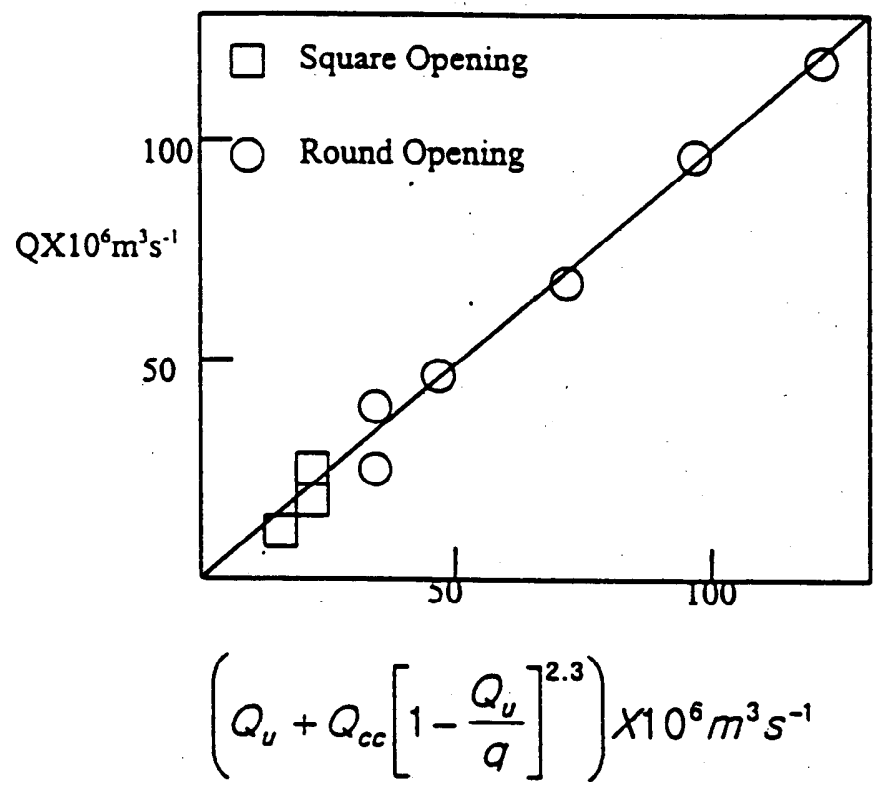

Fig 5 Measured exchange rates across a horizontal partition with two openings, unidirectional flow in one opening and countercurrent in the other, plotted against eq.(8) ( Fig.7 of Epstein and Kenton, 1989)

\subsubsection{Studies on buoyant jet flow}

Much research has been done to the study of transport by jets, plumes, and wall boundary layers in large-scale stratified systems. Several general references are available for mixing by free buoyant jets in stratified and unstratified environments(C.J. Chen and W.Rodi(1980),E.J.List(1982), B.Gebhart, Y.Jaluria, RL.Mahajan and B.Sammakia( 1988)). Peterson et al. (1993) derived a convenient scaling parameters for design of scaled experiments for reactor containment simulation. And also Peterson(1994) derived governing equations for mixing of stratified fluids in large enclosures.

\section{Experimental Investigation}

\subsection{Experimental Arrangement}

The experimental apparatus consisted of a clear plexiglass tank of rectangular geometry(test section) with an outlet valve connected to a calibration section. Probe is located at the exit of chimney in lower compartment and connected to the data acquisition section. Fig. 6 shows a sketch of the experimental arrangement. A rectangular tank has been fabricated with the interior region $0.578 \mathrm{~m}$ long, $0.289 \mathrm{~m}$ wide and $0.600 \mathrm{~m}$ high. The tank is made of plexiglass so as to allow flow visualization, for which videotaping technique is used. The grid lines were made using black threads at every $5 \mathrm{~cm}$ on the every sides of the wall to help visualization. A horizontal plexiglass partition plate located $0.289 \mathrm{~m}$ above the bottom of the tank divided the tank into an upper compartment and a lower compartment. The lower compartment was filled with pure water and the upper one with sugar water. The partition plate was placed on several supports attached along wall and completely sealed with duct tape. There were two openings at the center of every halfsize partition, which could hold chimneys of various heights. 


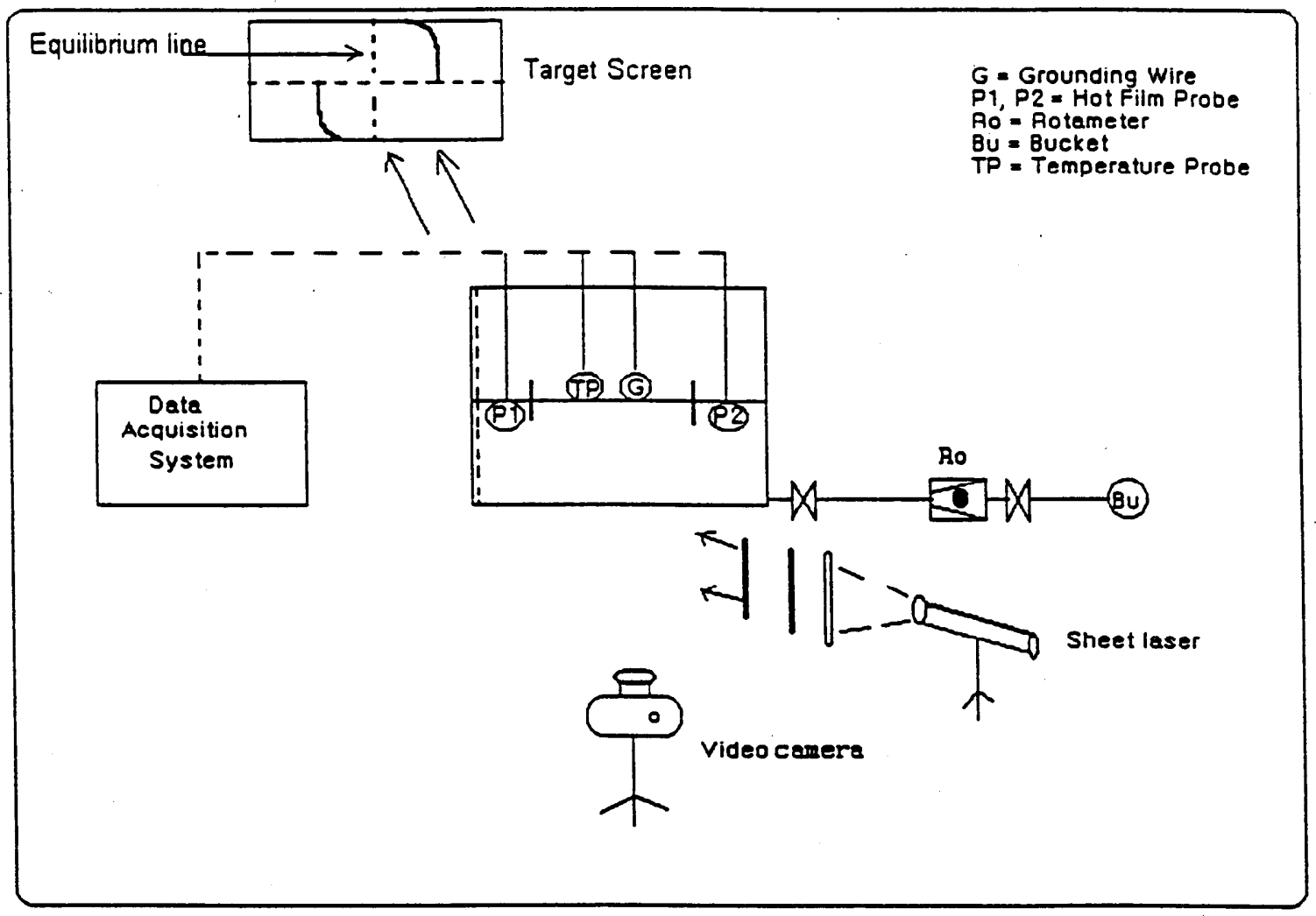

Fig.6 Experimental Facility

Two types of openings were employed in the experiments. In one case, the sugar-water flow was directed through a simple orifice, which was constructed by cutting a circular hole in a plexiglass partition sheet. In the other, the sugar-water flow passed through a plexiglass tube that was inserted and sealed with duct tape.

Two hot film probes were located at the exit of each chimney. They were all at the center of the chimney and maintained at the same location as during calibration. They were connected to controller with a water proof cable.

A temperature probe was located in the upper compartment to measure real-time temperature and compensate the resistance fluctuations due to the temperature variations.

Flow visualization was used to identify each flow pattern and to understand the ambient-flow stratification phenomena. The pulsating flow was well visualized to show the flow features contributing to the pulsating flow. By lighting the tank from behind with long fluorescent bulbs, the pulsating flow could be recorded on VHS tapes and analyzed later. White blank paper was attached on the back and side of the tank to evenly diffuse the reflected light from the opposing white wall.

Calibrations of hot film probes for each solution with different densities were required. A drainage hole was located at the bottom comer of the right hand side wall of the plexiglass tank and was connected to a hose via a valve. This hose was connected to a rotameter and a flow-control valve was located at the exit of the rotameter. The plexiglass 
tank was located on an elevated desk, so that calibration could be easily done by allowing gravity driven flow through the partition opening.

The vertical density variation was monitored using a light deflection technique. The idea is that the density changes in the medium make the value of the index of refraction change. Sheet laser was fabricated using 20 watt helium-neon laser and concave mirror. The light travels through air, tank wall, liquid, tank wall, air, and finally hits a white screen with grid lines on it. Figure 7 illustrates the method. The movement of the location of the light was monitored. During the test the target sheet was attached about $3 \mathrm{~m}$ away from tank wail. We noticed that the density variance of $30 \mathrm{~kg} / \mathrm{m}^{\wedge} 3$ makes light line move about $7.62 \mathrm{~cm}$.

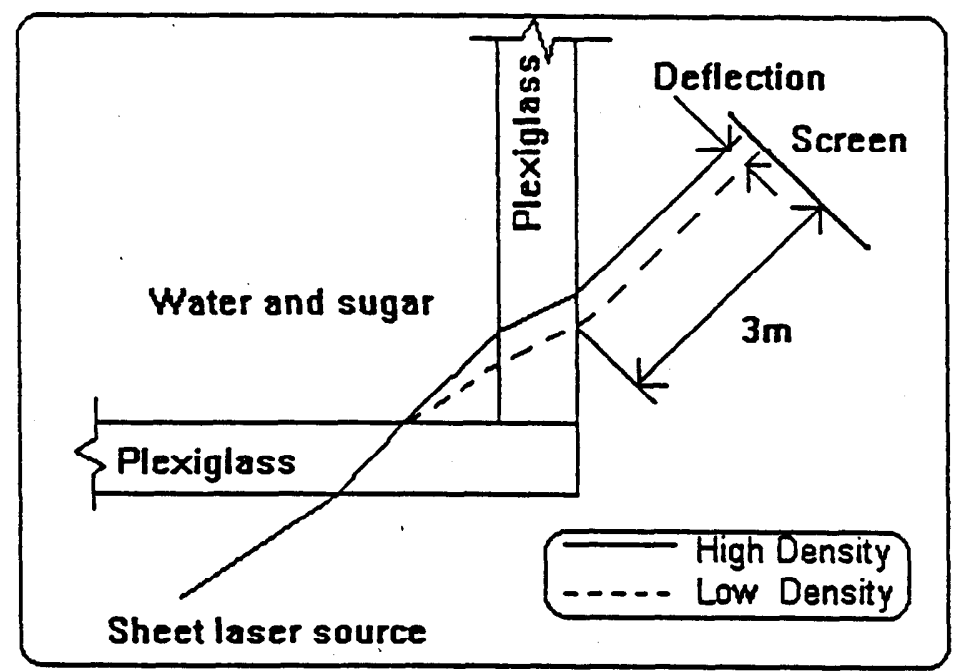

Fig. 7. Schematic showing method of measuring tank vertical density distribution with laser-light sheet using changing index of refraction.

Sheet laser that covers whole test section was fabricated with a helium-neon point laser and a filter that converts a point source to sheet laser. The density curve was recorded on SVHS video tape.

\subsection{Experimental Procedure}

\subsubsection{General Description}

A carpenter's level was used to make sure that the partition and chimneys were well leveled. A leakage test was done to see whether there was any leakage across the partition.

Before every run of the experiment, the water and sugar water were left in the storage tank overnight, to assume that the initial temperature and density were constant. Density was measured by means of hydrometer and temperature by thermocouple. The average density difference ratio was $\Delta \rho / \bar{\rho}=0.0476 \sim 0.0952$. The lower compartment was filled with pure water. The openings in the partition were then closed with rubber plugs, and then the upper compartment was filled with sugar water up to the $28.9 \mathrm{~cm}$ grid line. The sugar water was dyed to aid visualization.

A run was initiated by removing the rubber stopper instantaneously. A countercurrent exchange flow or a unidirectional flow of sugar water or water was then observed visually close. Flow rates were measured by means of Hot Film Probe. The voltage signal from the 


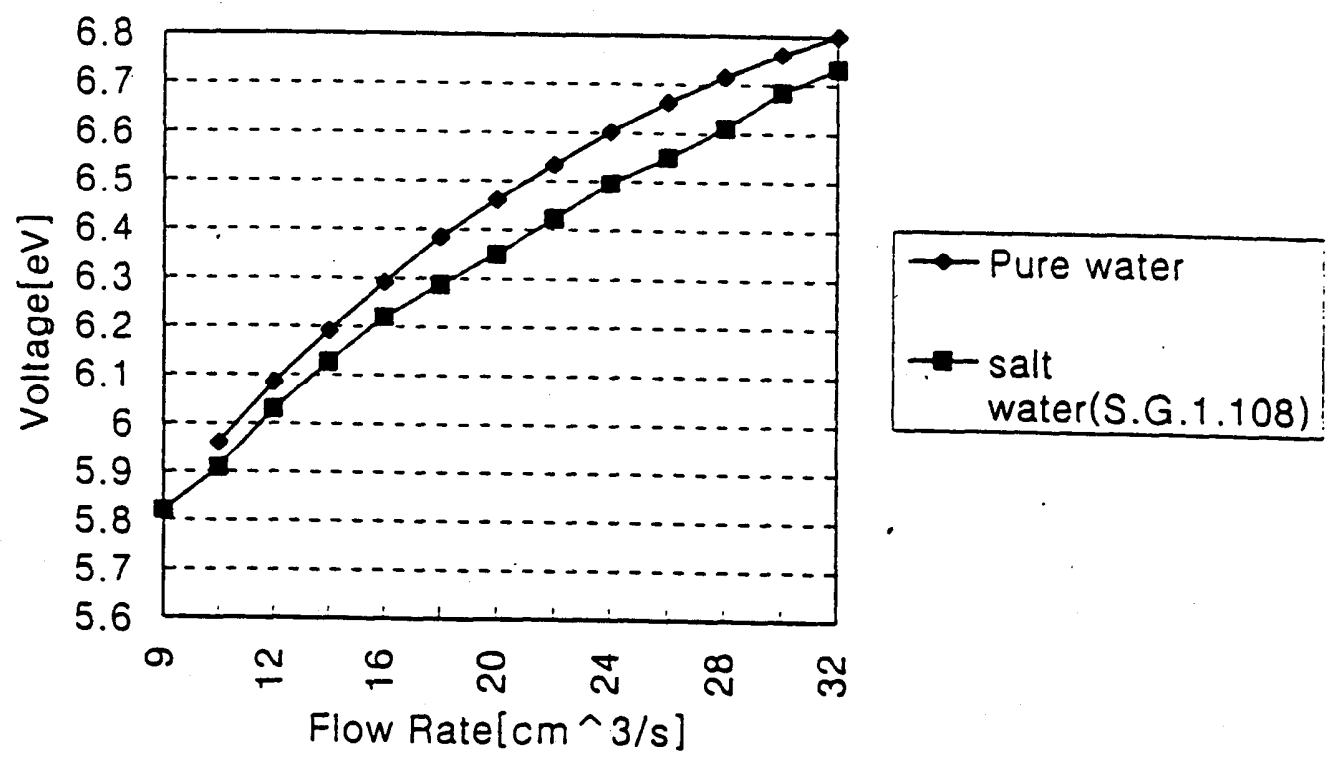

(c) Signal comparison of salt and pure water.

Fig.8 Calibration Curve

Fig. 9(a ) shows a schematic of the Probe and 9(b) is the principle of the probe measurement. $\mathbf{R}_{\mathbf{1}}, \mathbf{R}_{\mathbf{2}}$, and $\mathbf{R}_{\mathbf{L}}$ are adjustable resistors which have been previously calibrated, and $R_{w}$ represents the probe resistance. To use the bridge, the resistance of $R_{3}$ is adjusted until the galvanometer $G$ shows preset deflection. Initially points $E_{1}$ and $E_{2}$ must then be at the preset potential level. The resistance of the HFP changes as the fluid velocity changes. Due to the changes of the probe resistance the bridge becomes unbalanced. The error voltage $E_{2}-E_{1}$ will be a measure of the corresponding change in the wire resistance. These two voltages form the input to the operational amplifier. The selected amplifier has an output current, i, which is inversely proportional to the resistance change of the hot-wire sensor. Feeding this current back to the top of the bridge will restore the sensor's resistance to its original value.

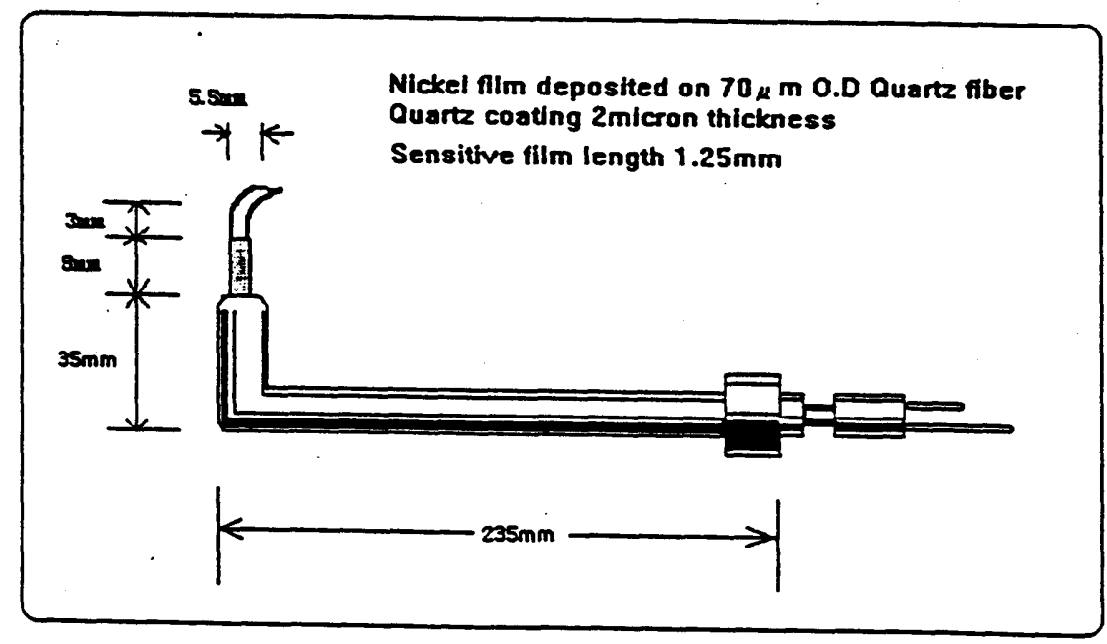

(a) Schematic of Probe 


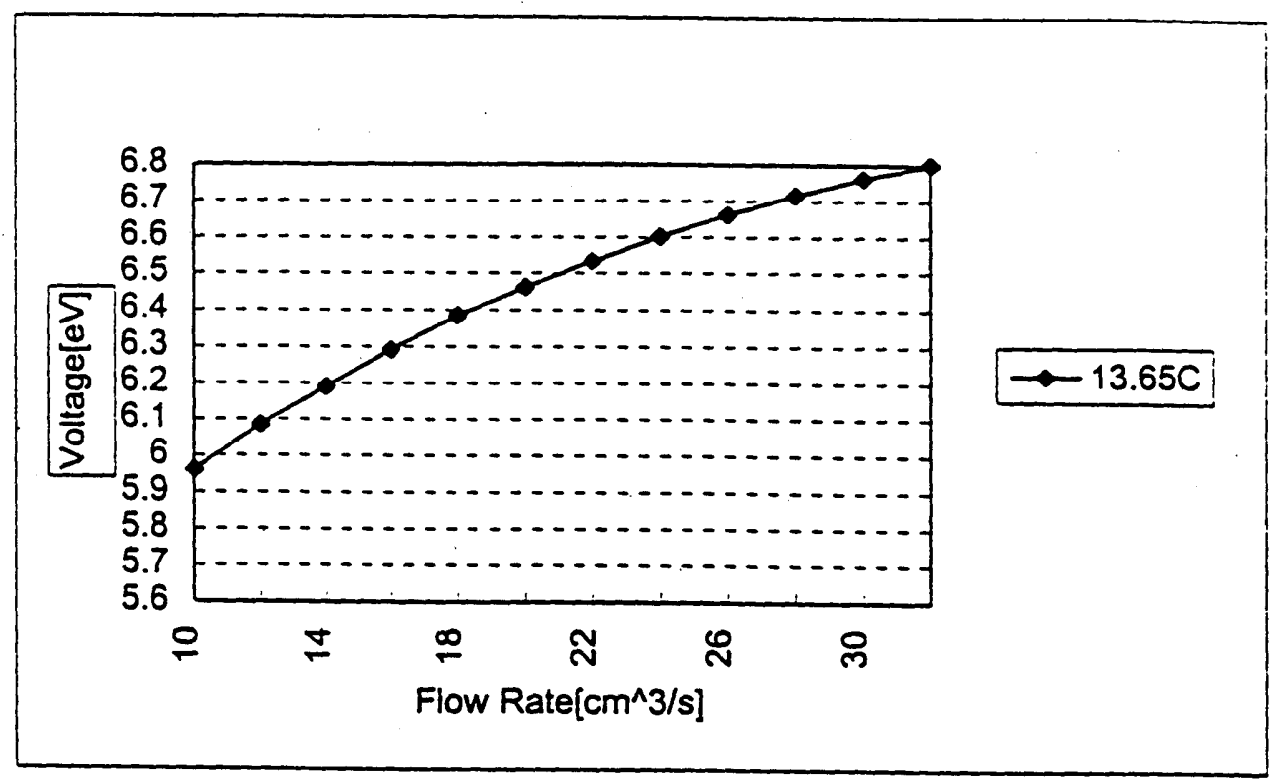

(a ) Pure Water calibration curve

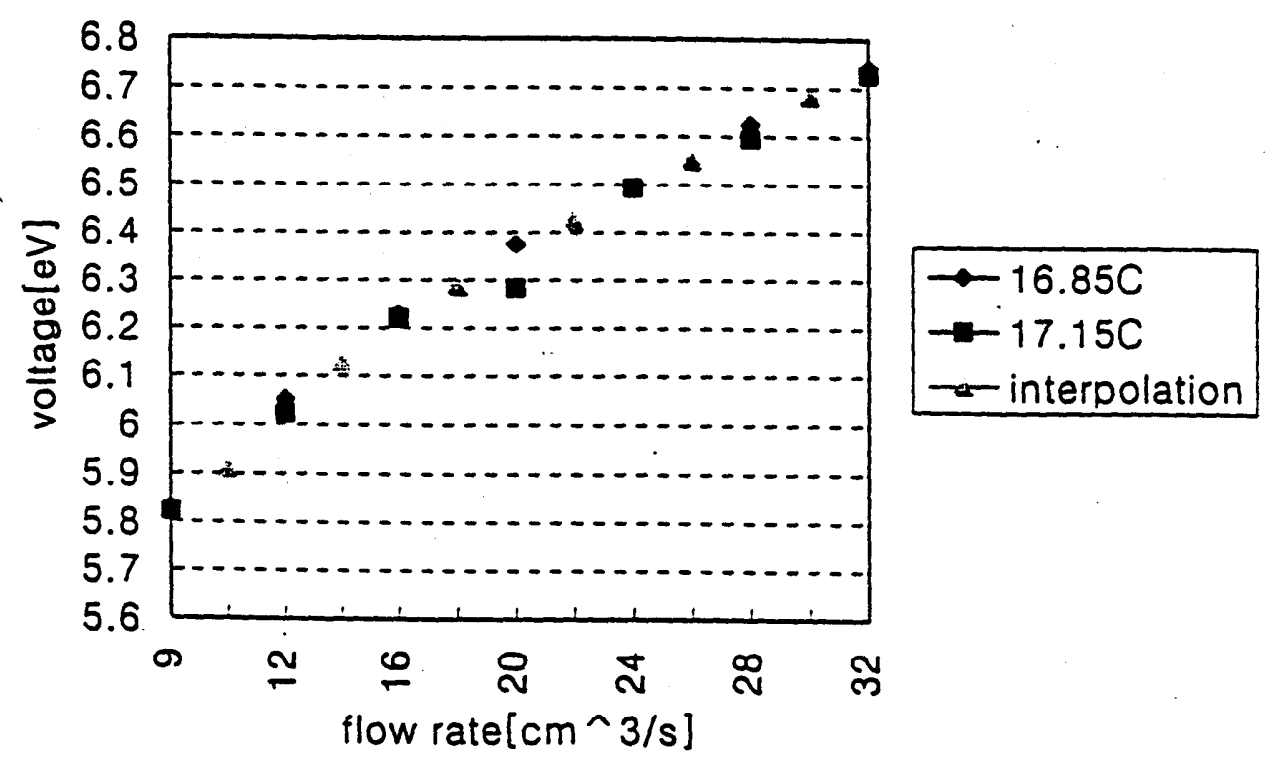

(b) Salt Water( $\mathrm{SG}=1.108$ ) Calibration Curve 
probe was converted into a digital signal stored in a PC. The stored information about flow rates were then converted into volumetric flow rate by using the calibration table developed using rotameter measurements. At the same time, density measurements were done using the light deflection technique by recording the test section and target sheet on VHS tape, Also a clock that displays minutes and seconds was placed right below the target sheet so as to record time with density variances.

\subsubsection{Calibration}

Before the experiment was run, the hot film probe(HFP), sheet laser, and rotameter were calibrated against test liquids.

\subsubsection{Hot Film Probe}

Because hot film probes(HFP) are very sensitive to the small variations of density and temperature, the HFP was calibrated for wide range of density $\left(1000 \sim 1100 \mathrm{~kg} / \mathrm{m}^{\wedge} 3\right)$ and temperature $\left(17 \sim 21^{\circ} \mathrm{C}\right)$ that the HFP experienced during the experiment. These calibration data were obtained by placing the hot film probe (HFP) at a fixed location below the partition opening. The HFP calibration provided a correlation between the anemometer voltage output recorded by the data acquisition system and the volumetric flow rates measured by the rotameter.

The followings is the procedure used for the HFP calibration.

- open one of two openings in the partition

- fill the tank with known fluid of certain density

- measure temperature by thermocouple

- setup the data acquisition system and check the functioning of the probe

- set the flow rate at a certain level using the rotameter and get steady state flow through drainage tube by controlling the valve

- read the voltage output on the PC screen and the rotameter measurement

- iterate the above procedures by changing the opening, the fluid density and flow level on Rotameter

- get a calibration curve by curve fitting of the above data

Fig. 8 shows some of the calibration results. From Fig.8( c), the maximum voltage output difference between pure and salt water at constant flow rate was calculated as $0.07 \mathrm{~V}$. And the voltage difference over the whole flow rate range that the probe experiences during experiment runs was calculated as $0.79 \mathrm{~V}$. So, the density effect is $8.86 \%$ deviation of voltage output and flow rate of $2\left[\mathrm{~cm}^{\wedge} 3 / \mathrm{sec}\right]$ corresponding to $8 \%$ for $\mathrm{L} / \mathrm{D}=3.149$. 


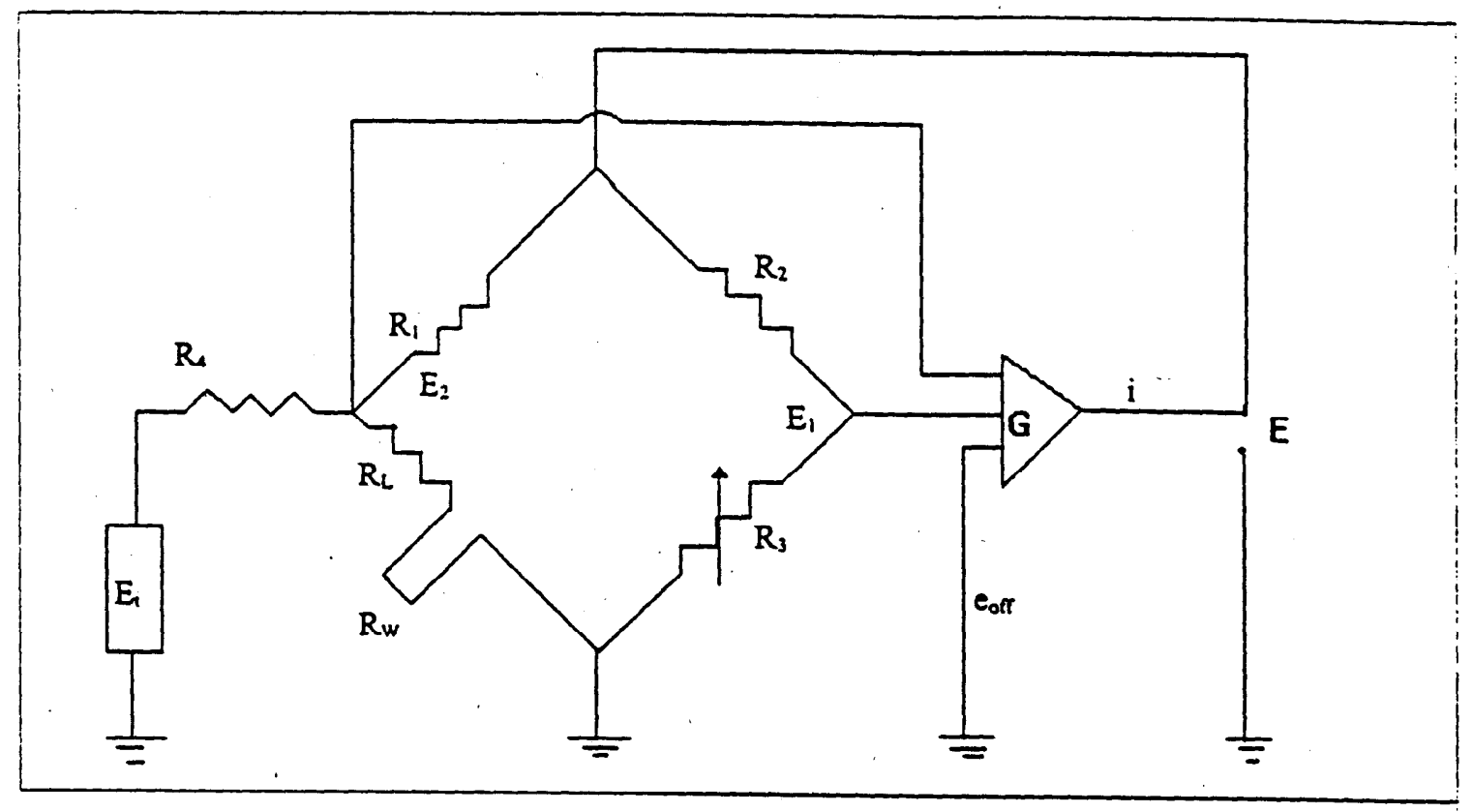

( b) Constant Temperature Anemometer containing a Wheatstone Bridge.

Fig.9 Schematic of Probe (a ) and (b) Anemometer Wheatstone Bridge.

\subsubsection{Sheet Laser}

The deflection length for the density range of 1000 to $1100\left[\mathrm{~kg} / \mathrm{m}^{\wedge} 3\right]$ was obtained by monitoring the location of the light line on target screen.

\subsubsection{Rotameter}

An Omega Engineering Rotameter model FL-104 was used. It can measure wide range of flow rates by simply changing float balls. To calibrate the rotameter, the fluid density is measured using a hygrometer. The whole tank was filled with test liquid and drained through a $1.27 \mathrm{~cm}$ diameter tube. For calibration it was confirmed that the tube was filled with test liquid without air. By controlling the control valve, a steady state flow through rotameter was obtained. The liquid was drained into 5-liter scaled container. At the same time, the time taken to fill each liter and the level of Rotameter ball were marked on record a sheet. The flow rate could then be calculated as

$Q=l / \Delta t$

where $\mathrm{Q}$ is the volumetric flow rate, At the time period, and $\ell$ the liquid level change in the scaled-container.

By iterating this procedure, the Rotameter was calibrated for the density range of 1000 to $1100\left[\mathrm{~kg} / \mathrm{m}^{\wedge} 3\right]$. Fig.10 shows one of the calibration curves.

\subsubsection{Measurement}

\subsubsection{Density Measurement}

The sheet laser was passed vertically through the comer of the tank as shown in Fig.7. As density changed, the index of refraction of the stratified ambient fluid changed and consequently the density curve on the target sheet shifted. The density curve in the target sheet was recorded by video-camera. At the same time, the digitalclock displaying minutes 
and seconds was recorded with the target sheet. These curves were converted into density data by curve fitting of appropriate calibration data.

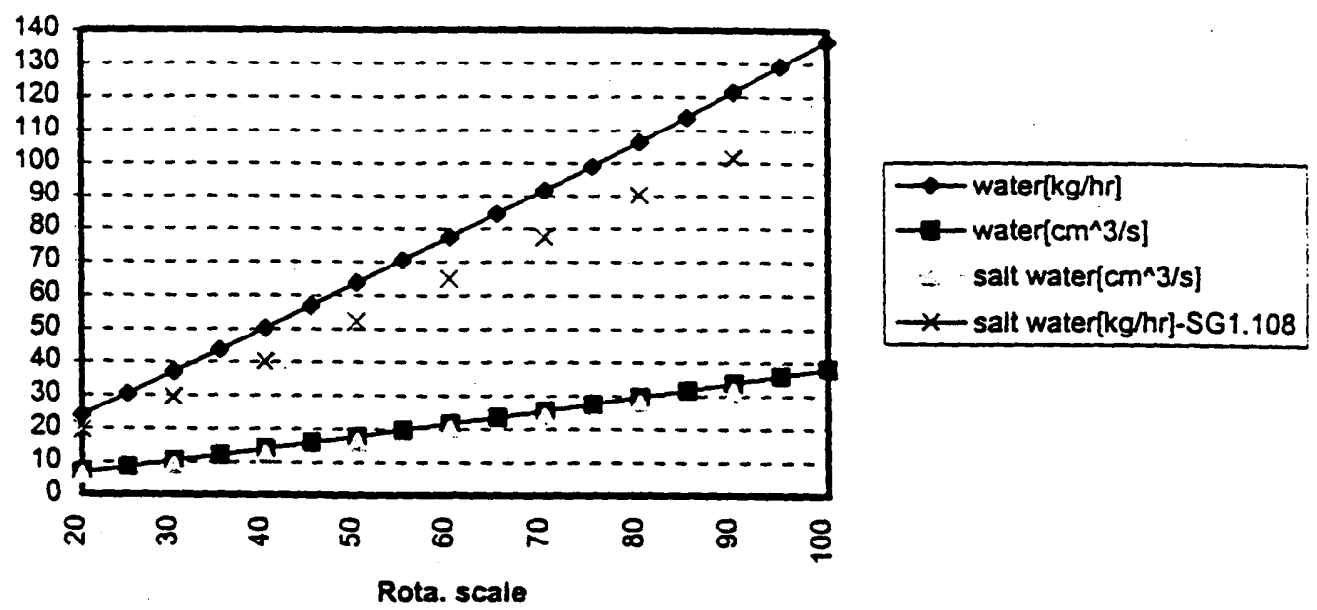

Fig.10 Rotameter calibration curve.

\subsubsection{Flow Rate Measurement}

Exchange flow velocities were measured using a 70micron diameter nickel HFP connected to a DANTEC model 55R14 constant temperature anemometer. The HFP can measure the flow rate range of $0.01 \sim 10 \mathrm{~m} / \mathrm{s}$, where the voltage is in the range of $0 \sim 10 \mathrm{~V}$ with water.

The HFP works on the principle of balancing the Wheatstone bridge- see 3.2.2.1. The voltage signal is sent to data acquisition system.

The data acquisition system consisted of

- Frame(Texminal Panel): Frame was Streamline model CTA 90C10, consisting of three channels. All temperature and voltage from anemometer corresponding to the flow rate were wired to the CTA 90C10 panel.

- Analog to Digital Conversion Card: The 'Frame was connected to National Instruments AT-MIO-16E-1 CARD mounted on PC. This converts the analog input signal to a digital signal that can be read by computer.

- Data Acquisition Software: StreamWare Application Software on PC can acquire data from any instrument or transducer with analog output through the A/D board(s) in the PC. It works in the Windows environment with the ordinary Windows element. Therefore, the data can be easily edited.

\section{Results of preliminary experiments and Discussion}

\subsection{Preliminary Experiments}

Four circular openings of different diameters and length were made from acrylic tubes or holes cut in the partition. The diameters of the openings were $1.588,1.905$, and $5.08 \mathrm{~cm}$, and the length of the openings were $0.159,0.635$, and $5.0 \mathrm{~cm}$. This combination of orifices and chimneys resulted in L/D ratios of $0.0313,0.0835,0.333$, and 3.149 . Tests were carried 


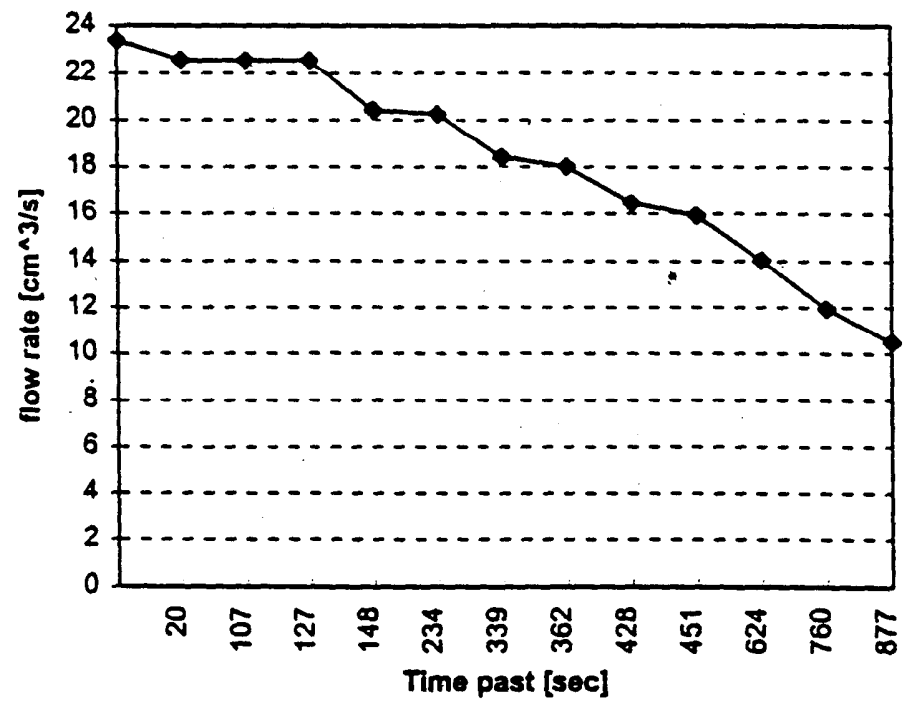

$\rightarrow$ measured flow rate[cm^3/s]

(a) Measured Flow Rate with Salt Water and Pure Water $\left(\rho_{H}+\rho_{L}=2100 \mathrm{~kg} / \mathrm{m}^{\wedge} 3\right)$.
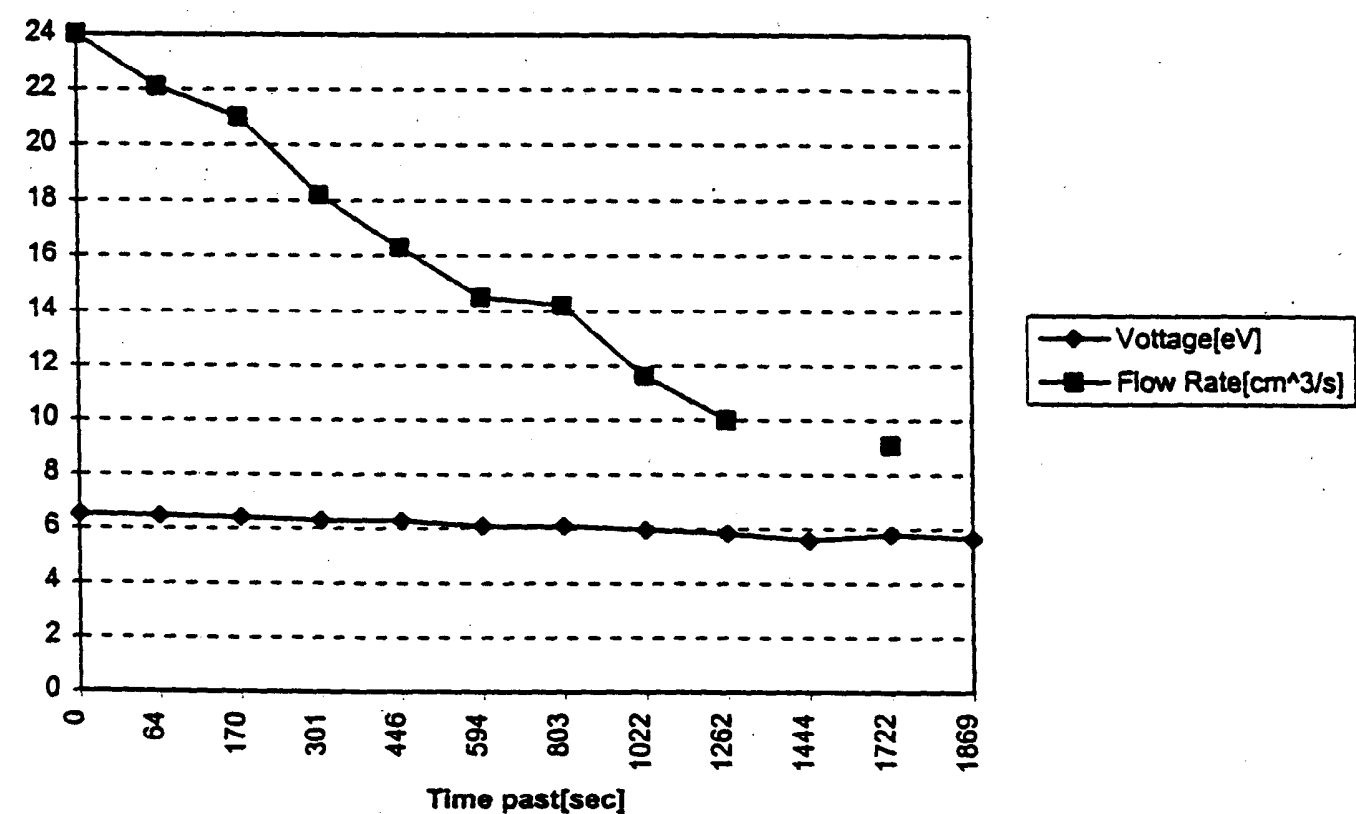

(b) Measured flow rate with sugar water and pure water $\left(\rho_{\mathrm{H}}+\rho_{\mathrm{L}}=2060 \mathrm{~kg} / \mathrm{m}^{\wedge} 3\right)$.

Fig.13 Measured flow rate with $\Delta p=60\left[\mathrm{~kg} / \mathrm{m}^{\wedge} 3\right]$. 


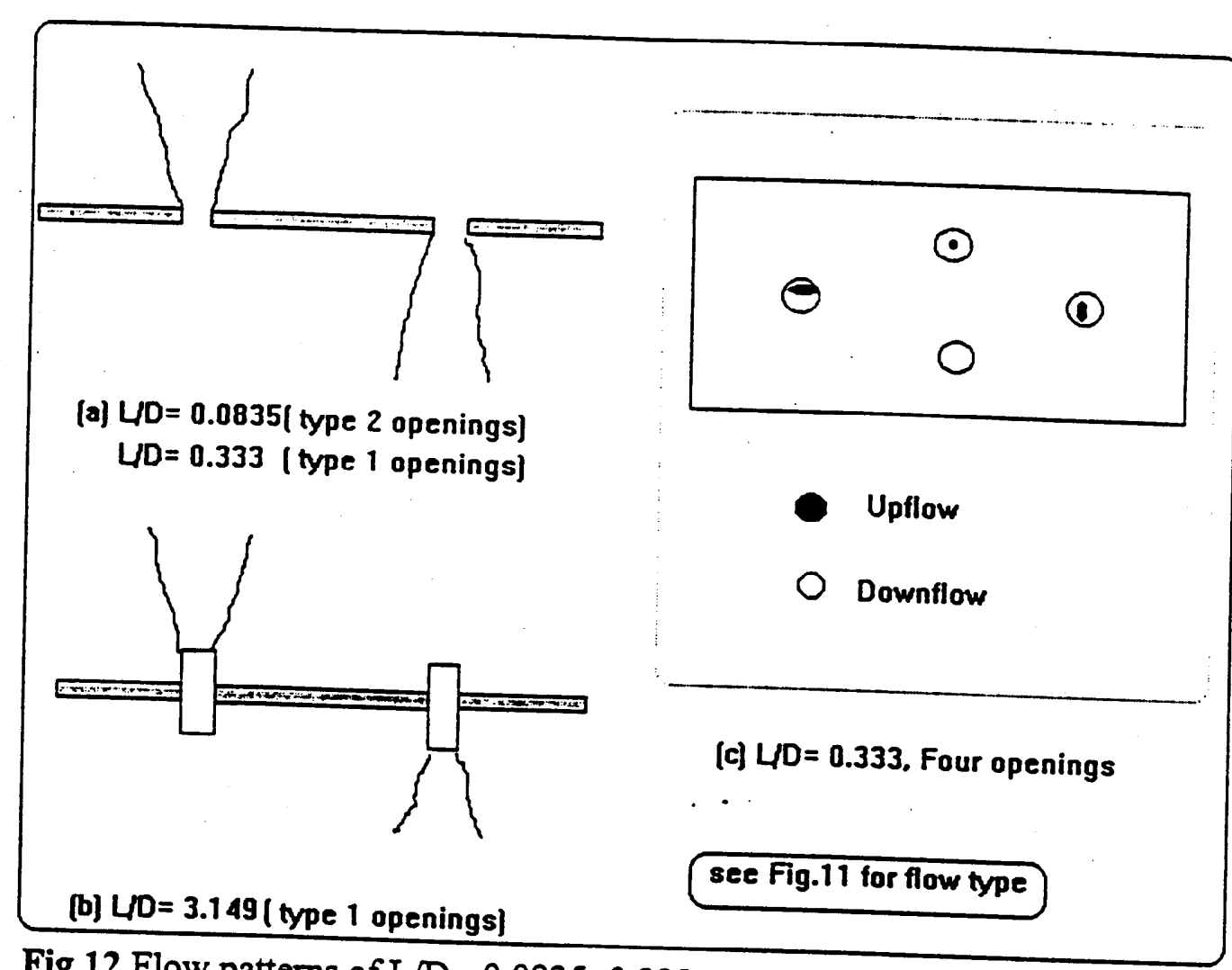

Fig.12 Flow patterns of $L / D=0.0835,0.333$, and 3.149 with multiple openings.

For $\mathrm{L} / \mathrm{D}=0.0835,0.333$ and 3.149 with two openings, only one-direction flow was observed See Fig. 12(a ),(b)). But, if the number of holes is more than two, it is hard to tell what the flow pattern will be(See Fig.12(c )). As shown in (c), bidirectional flow exists in $\mathrm{L} / \mathrm{D}=0.333$, even though that aspect ratio didn't have bidirectional flow for the two openings configuration.

Primarily one direction flow with two openings have been studied. And the flow rate was measured with $\mathrm{L} / \mathrm{D}=3.149$ and the resultant flow rate curve is shown in the Fig. 13 The initial flow rate is well agree with the value calculated from equation 6 with the coefficient of 1.06 rather than the coefficient of 0.805 . Those data are available in Table 1 But, right after two fluids reach at the level of partition, the flow rate is unpredictable because no density information is available.

Strong stratification induced by density gradients is observed in enclosure all through the experiments. A one-dimensional density distribution can be considered to model the mixing processes.

Table 1 Initial flow rate data

\begin{tabular}{|l|r|r|l|}
\hline & $\begin{array}{l}\text { Equation 6 with } \\
\left.\text { Coef.=1.06[ } \mathrm{cm}^{\wedge} 3 / \mathrm{s}\right]\end{array}$ & $\begin{array}{l}\text { Equation 6 with } \\
\left.\text { Coef. =0.805[ } \mathrm{cm}^{\wedge} 3 / \mathrm{s}\right]\end{array}$ & $\begin{array}{l}\text { Experiment } \\
\text { Result }\left[\mathrm{cm}^{\wedge} \text { 3/s }\right]\end{array}$ \\
\hline Brine/water & 24.846 & 18.87 & 23.3 \\
\hline Sugar/water & 25.086 & 19.051 & 24 \\
\hline
\end{tabular}


out with average sugar densities in the range of $1050 \sim 1100 \mathrm{~kg} / \mathrm{m}^{\wedge} 3$ over the duration of a run.

Four different geometric variations were tried to, see how the ratio of the L/D and W/D influence to the flow pattern. Also the flow pattern with four holes was recorded by videocamera. Fig. 11, 12 show how the flow pattern varies as the L/D ratio and geometry varies.

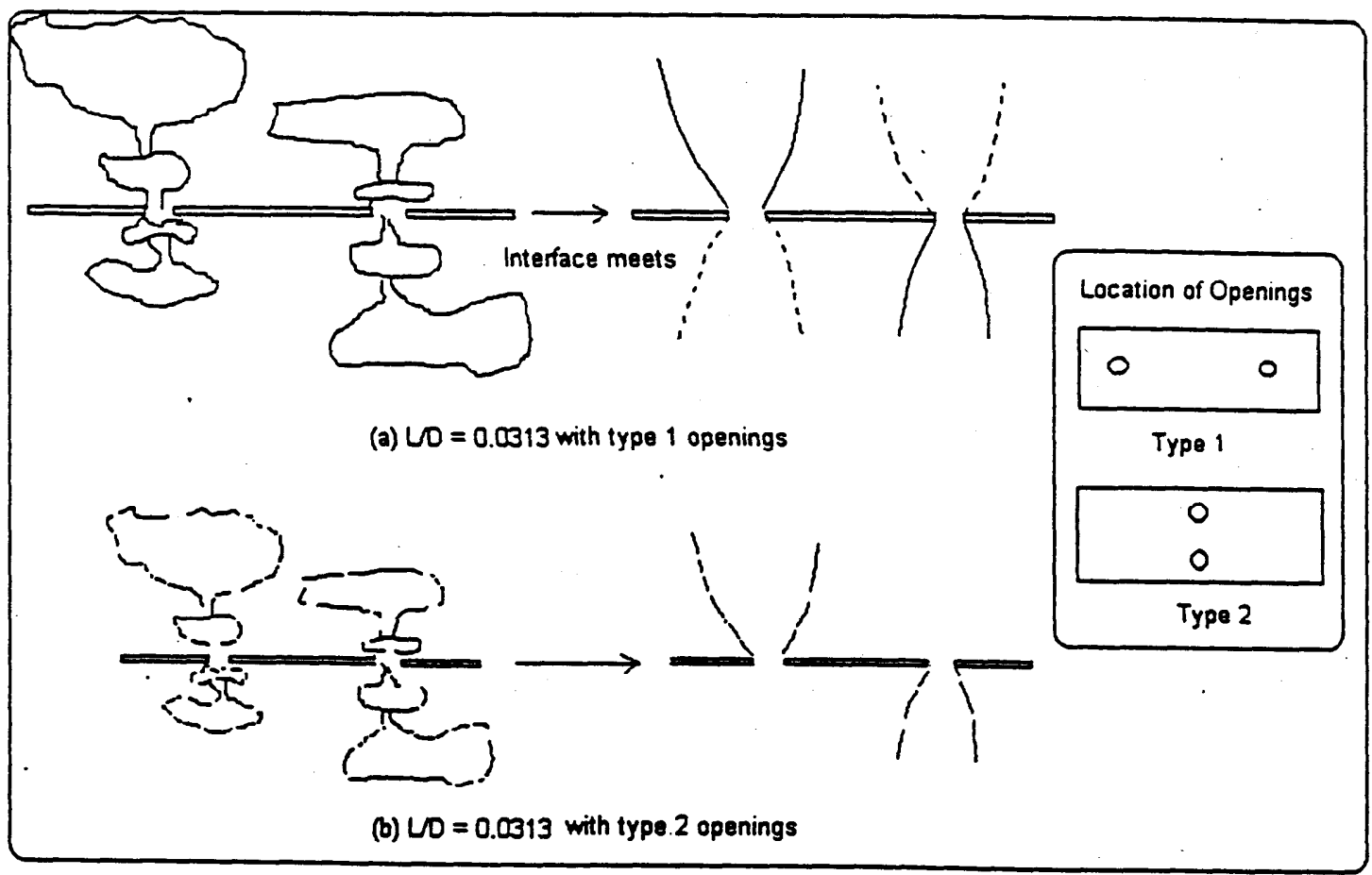

Fig. 11 The flow pattern of $\mathrm{L} / \mathrm{D}=0.0313$

As shown in Fig. 11, for $\mathrm{L} / \mathrm{D}=0.0313$ Rayleigh-Taylor type instability was observed in each hole. This flow pattern is called as oscillatory exchange flow, a flow regime analyzed by M.Epstein (1988) and T.A.Conover, R.Kumar, and J.S.Kapat (1995). Very interesting flow behavior was observed when the two interfaces of upper and lower compartment met at the partition, where the interface is defined as the first front toward the partition whose density increase is above the density increase near partition in lower compartment, vice versa for upper compartment. Suddenly the oscillatory flow was damped and unidirectional flow was initiated in each hole. Periodically the one-direction flow oscillated up and down until system reached an equilibrium state (See Fig.11(a )). To see the influence of the spacing between openings, a column opening was tested as shown in Fig. 11 (b). The flow behavior was very similar except that the one-direction oscillating flow was not apparent as case (a). But it is sure that there is some effect from W/D and gravitational wave movements at partition from convection flow. But, further study for the effect of W/D is left behind. 


\subsection{Uncertainty Analysis}

- HFP; Because probe is very sensitive to temperature fluctuations, it is necessary to use an appropriate calibration table to produce the best representative data. Usually interpolation data are retrieved from the limited experimental data. The other factors that can lead to significant calibration shifts are air bubble formation on the probe and probe contamination. The early hot-wire and hot-film studies revealed that under certain conditions gas bubbles formed on the probe element, leading to significant calibration shifts. The work of Rasmussen( 1967) demonstrated that this was due to the thermal formation of bubbles on a heated surface immersed in air-saturated water. It was observed that the bubbles of a certain size were already suspended in the water flow. To minimize this problem, it is recommended that the water is allowed to stand before use and that cascading in air is avoided by using a submerged return/filler pipe in a water tank. The bubble-formation problem can usually be eliminated by restricting the temperature difference, $T_{w}-T_{2}$, between the film and water to about $20^{\circ} \mathrm{C}$. The corresponding overheat ratio, $R_{w} / R_{s}$, is about 1.05-1.1 depending on the film material.

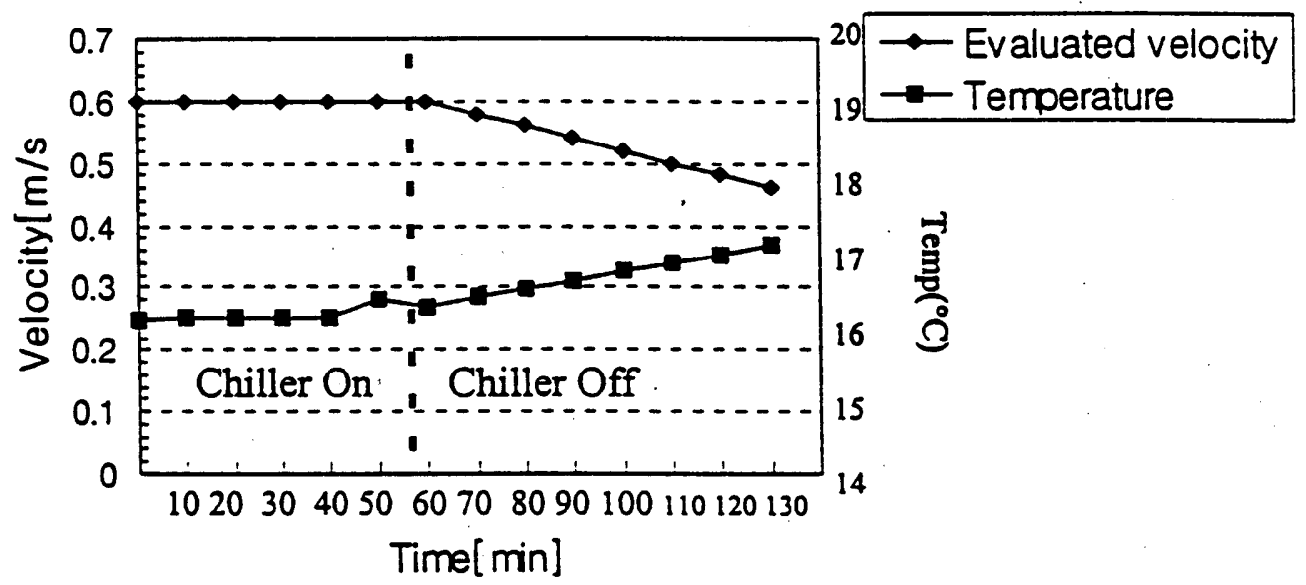

Fig.14 The stability of a hot-film probe in water:(a) with water temperature control(chiller on), and (b) variation in the water temperature and hot-wire signal when the chiller is-turned off (Brunn,1995).

Probe fouling can be a major problem due to the gradual build up of scale, algae, and minerals on the probe, causing a shift in the calibration and a loss of sensitivity. Cylindrical hot-probes are prone to contamination by particles sticking to the fiber element. Brunn (1995) showed that there are two integrated modifications to the flow loop that have virtually eliminated both the probe-contamination and temperature-drift problem. Firstly, a bypass chiller unit was connected to the storage tank and water drawn from the tank was bypassed through the cooler unit and returned to the tank. Secondly, in the connected pipe between the tank and the chiller, two filtration units $(8 \mu \mathrm{m}$ and $2 \mu \mathrm{m})$ have been installed. The corresponding improvement in the long-term stability of the hot-film probe is demonstrated in Fig.14. When the chiller is on, the. water temperature can be seen to remain virtually constant and, during a period of $60 \mathrm{~min}$ with a constant-flow condition, the anemometer output voltage, and consequently the interpreted velocity, didn't change. The effect of temperature variation is also demonstrated in Fig.14. With the chiller turned off, 
the water temperature was observed to rise linearly with time at a rate of $21-25 \% / \mathrm{hr}$. It is therefore essential to control the water temperature in order to obtain reliable hot-film results, and filtration is also necessary to avoid probe contamination. For this experiment, to satisfy these two requirements, water was allowed to stand in the tank overnight. Instead of installing filters, as $\mathrm{Wu}$ and Bose( 1993) recommended, the probe was aged in running water for about 20 minutes. This precontamination aging is believed to slow the drift considerably, and allow each test run to be considered as a unit with a constant calibration characteristics.

- Rotameter Reading; $\pm 1(= \pm 1.43 \mathrm{~kg} / \mathrm{hr}$ water $)$

- Hygrometer; $\pm 0.001 \mathrm{~S} . \mathrm{G}\left(= \pm 1 \mathrm{~kg} / \mathrm{m}^{\wedge} 3\right)$

- Density Measurement; $\pm 1 \mathrm{~mm}$ resolution $\left(=0.8 \mathrm{~kg} / \mathrm{m}^{\wedge} 3\right)$

\section{Conclusion and Future Works}

Considering current experimental data, it seems that the flow patterns are independent on the density differences, but strongly depend on L/D ratio, the number of openings and W/D ratio. Also it was confirmed by several tests varying $\Delta \rho$ in the range of $10 \sim 100$ $\mathrm{kg} / \mathrm{m}^{\wedge} 3$. I didn’t observe any change, on the flow patterns for $\mathrm{L} / \mathrm{D}=3.149$.

Referring to the video image for $\mathrm{L} / \mathrm{D}=3.149$ shown in Fig. 15, it is apparent that the volume between both chimney exits doesn't participate in mixing process for relatively long term. In other words, the density induced strong stratification is observed and mixing by diffusion is negligible. So, one-dimensional numerical analysis can be the correct approach to model this specific system.

While running preliminary experiments, the HFP had some problem in salt water. Not only bubbles sitting on probe but also bridge was out of order just few minutes after exchange flow was initiated. So, it was required to switch the test liquid from salt water to sugar water that doesn't cause the same problem.

Small temperature and density variance caused significant calibration shift as illustrated in Fig.8 and Fig. 14. So, large amount of calibration works are required to produce reliable experimental results.

Due to the limited time, only $\mathrm{L} / \mathrm{D}=3.149$ could be tested in detail. So, in the future experiments, more other parameters need to be considered to see the effect of W/D and L/D.

One of peers in TH-Group is writing one-dimensional numerical code. It will be very interesting to compare this code with experimental results. 

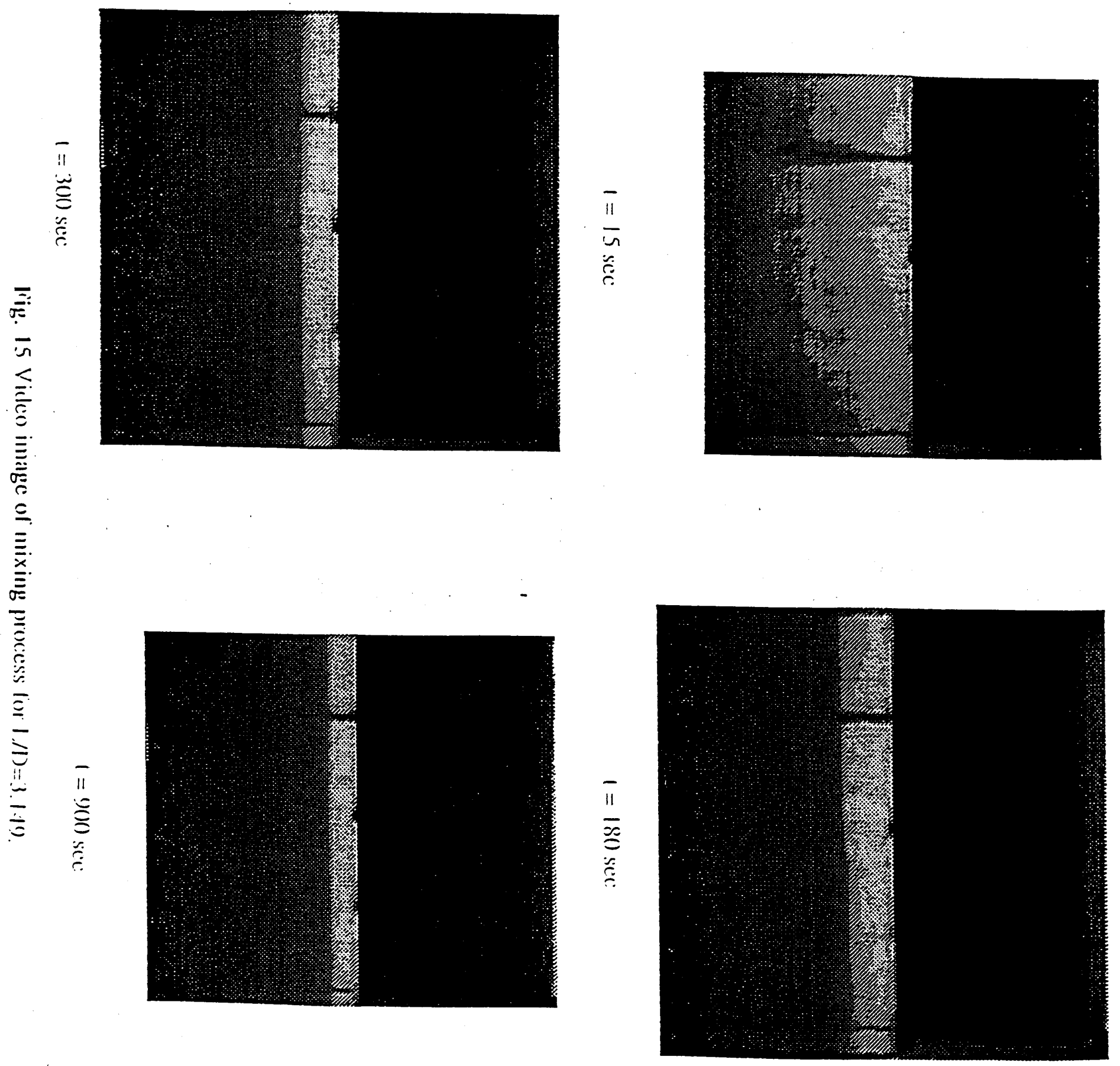


\section{References}

Brown, W., 1962, " Natural convection through Rectangular Openings in Partitions-2 Horizontal Partitions," Int. J. Heat Mass Transfer, Vol. 5, pp.869-878.

Epstein, M., 1988, "Buoyancy-Driven Exchange Flow Through Small Openings in Horizontal Partitions," ASME Journal of Heat Transfer, Vol. 110, pp. 885-893.

Epstein, M., and Kenton, M., 1989, " Combined Natural Convection and Forced Flow through Small Openings in a Horizontal Partition, With Special Reference to Flows in Multicompartment Enclosures," ASME Journal of Heat Transfer, Vol. 111, pp. 980-987.

Steckler, K. D., Baum, H., and Quintiere, J.G., 1986, " Salt water modeling of Fire Induced Flows in Multicompartment Enclosures," 21st Symposium (Int.) on Combustion, The Combustion Institute, Pittsburgh, PA, pp. 143-149.

C.J.Chen and W.Rodi, "Vertical Turbulent Jets: A Review of Experimental Data" Pergamon Press, New York (1980).

E.J.List, "Mechanics of turbulent buoyant jets and plumes"(edited by W.Rodi).Pergamon Press, New York (1988).

B.Gebhart, Y.Jaluria, RL.Mahajan and B.Sammakia, "Buoyancy-Induced Flows and Transport." Hemisphere, New York (1988).

N.Zuber, "An Integrated structure and scaling methodology for severe accident technical issue resolution, Appendix D, NURE/CR-5809." U.S. Nuclear Regulatory Commission(1991).

G.H.Jirka, “ Turbulent buoyant jets in shallow fluid layers. In Turbulent Buoyant Jets and Plumes(edited by W.Rodi)." Pergamon Press. New York (1982).

P.F.Peterson, V.E.Schrock and RGreif, "Scaling for integral simulation of mixing in large, stratified volumes", Sixth International Topical Meeting on Nuclear Reactor Thermal Hydraulics (NURETH-6), 5-8 October, Grenoble, France, Vol. 1, pp.201-211( 1993).

P.F.Peterson, "Scaling and analysis of mixing in large stratified volumes", Int. J. of Heat and Mass Transfer, vol.37, pp.970-106( 1994).

C.G.Rasmussen, " The air bubble problem in water flow hot-film anemometry", DISA Info., No.5,pp. 21-26(1967).

H.H.Brunn, "Hot-wire Anemometry-principles and signal analysis",Oxford university press,(1995).

S. Wu and N. Bose, "calibration of a wedge-shaped hot-film probe in a towing tank.", Measu. Sci. Technol., vol. 4, pp.101-108(1993). 


\section{Appendix B Results of Benchmark Test Results}

As described in Appendix A, a new technique based on sheet laser deflection was developed to measure the local concentration distributions in water systems. This method allows us to measure in detail the transient vertical distribution of concentration that occurs due to exchange flows from a perforated ceiling into a large volume. The results will be used to compare with the numerical model to improve the calculations for the mixing of oxygen entering an inerted waste tank following loss of ventilation.

Four tests has been performed using the above technique to measure the density distribution of sugar and salt water in the lower compartment. The lower compartment was initially filled with pure water and upper one with sugar or salt water. The vent height is $5.2 \mathrm{~cm}$ with an inner diameter of $1.5 \mathrm{~cm}$. The flow is unidirectional with two openings. Figures 1 and 2 shows the results with initial sugar-water density of 1.05 and 1.086 , respectively. Figures 3 and 4 shows the results with initial salt-water density of 1.19 and 1.1, respectively. Based on the density distribution, the flow rate through the opening was calculated from Eq.(6) in Appendix A, and the results were shown in Figures 5 and 6

Note that the dense plume of sugar-water falls to the bottom of the tank, entraining the ambient fluid. At early times the highly-diluted sugar water accumulates in a layer at the bottom of the tank. The interface between the diluted sugar water and the clear water moves upward with time, as the clear water is gradually entrained in the falling plume and mixed with sugar water. This mixing process corresponds qualitatively with the mixing and dilution that occurrs in inerted waste tanks after loss of ventilation, due to exchange flows with denser outside air through opening in the tank cover.

Within the next two months we will have model comparisons completed with this data and the new BMIX model currently under development. 


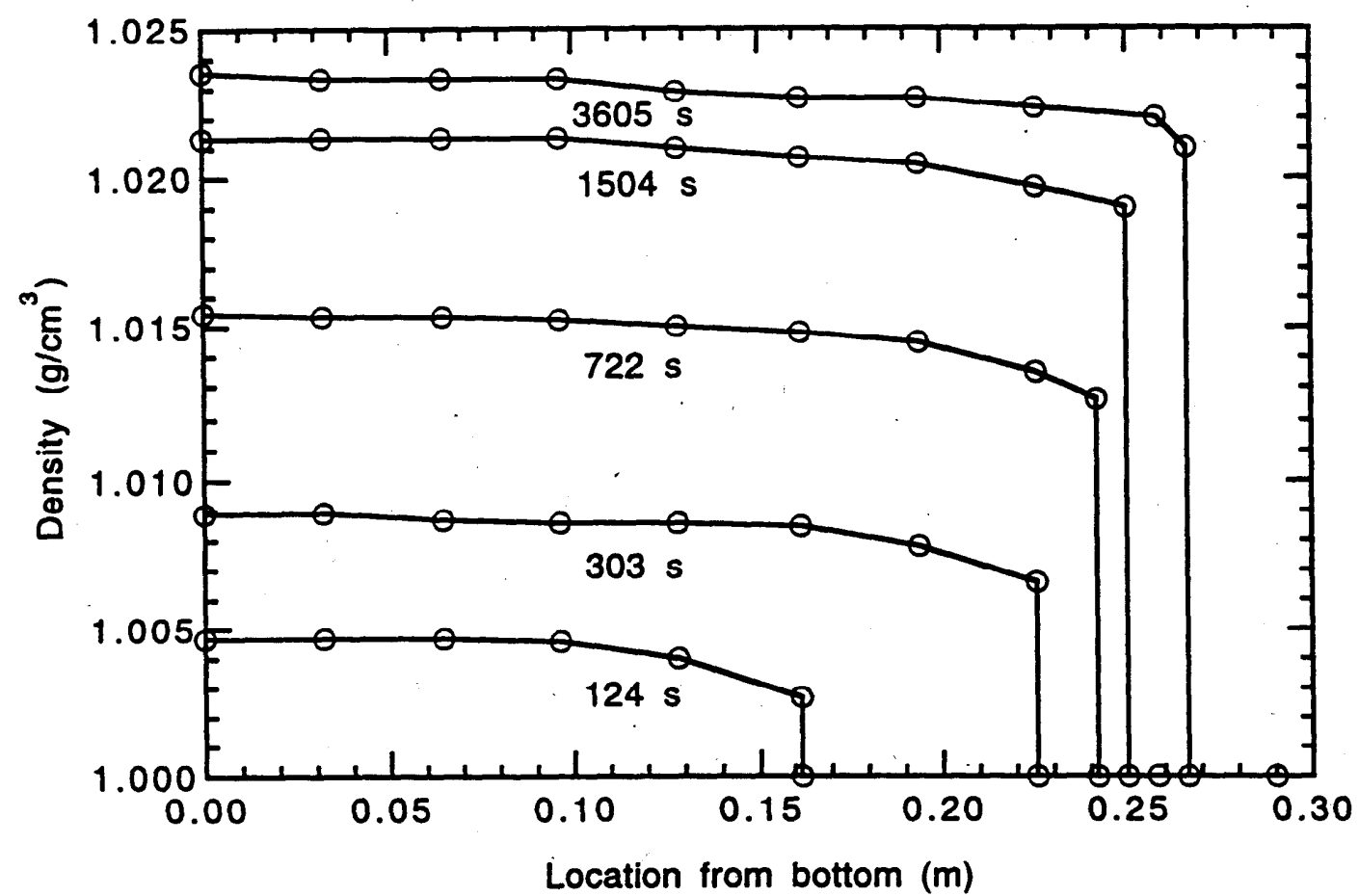

Figure 1 Density distribution for sugar water with initial condition of density $1 \mathrm{~g} / \mathrm{cm}^{3}$ at lower compartment and 1.05 at upper compartment

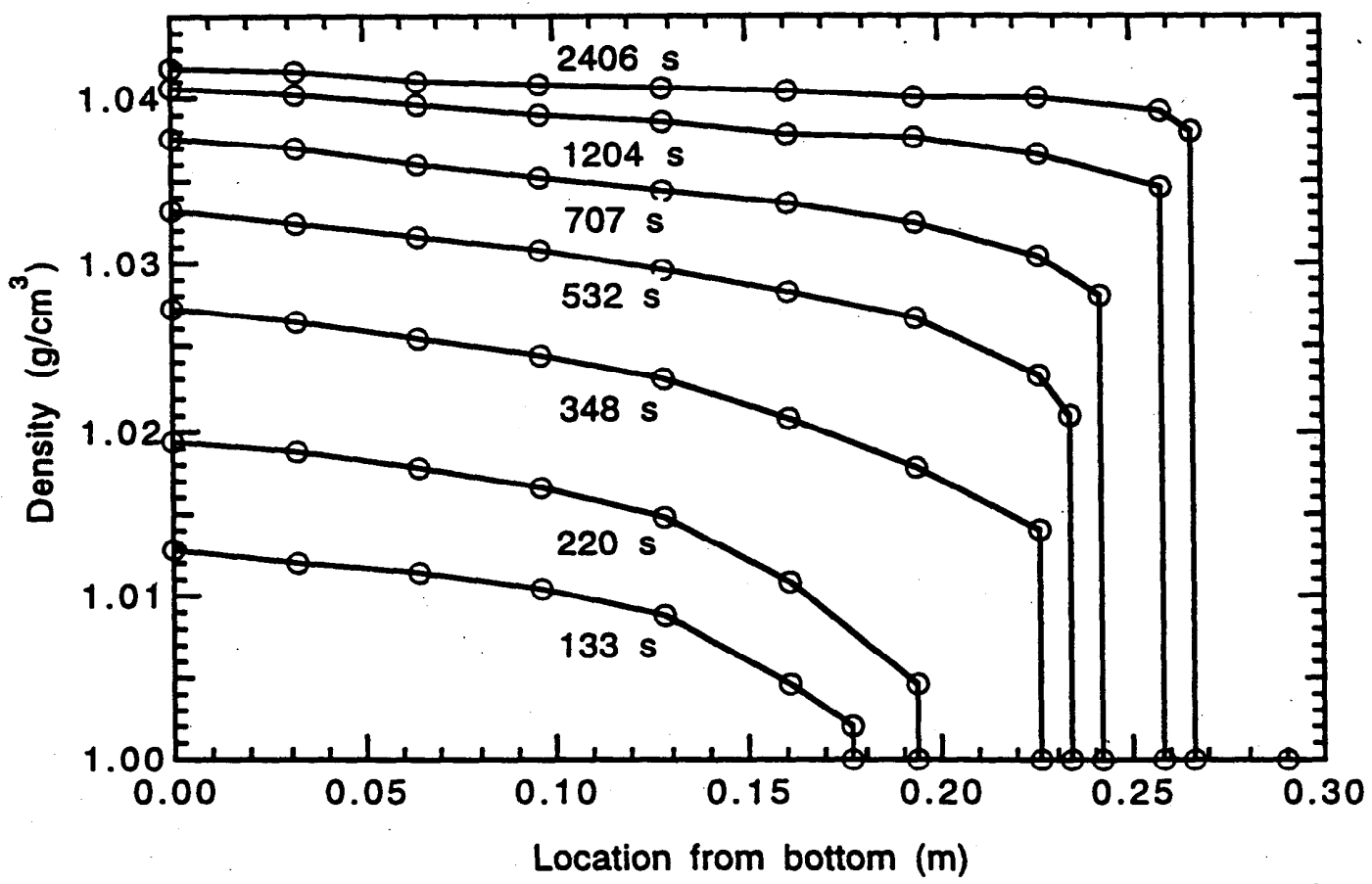

Figure 2 Density distribution for sugar water with initial condition of density $1 \mathrm{~g} / \mathrm{cm}^{3}$ at lower compartment and 1.086 at upper compartment 


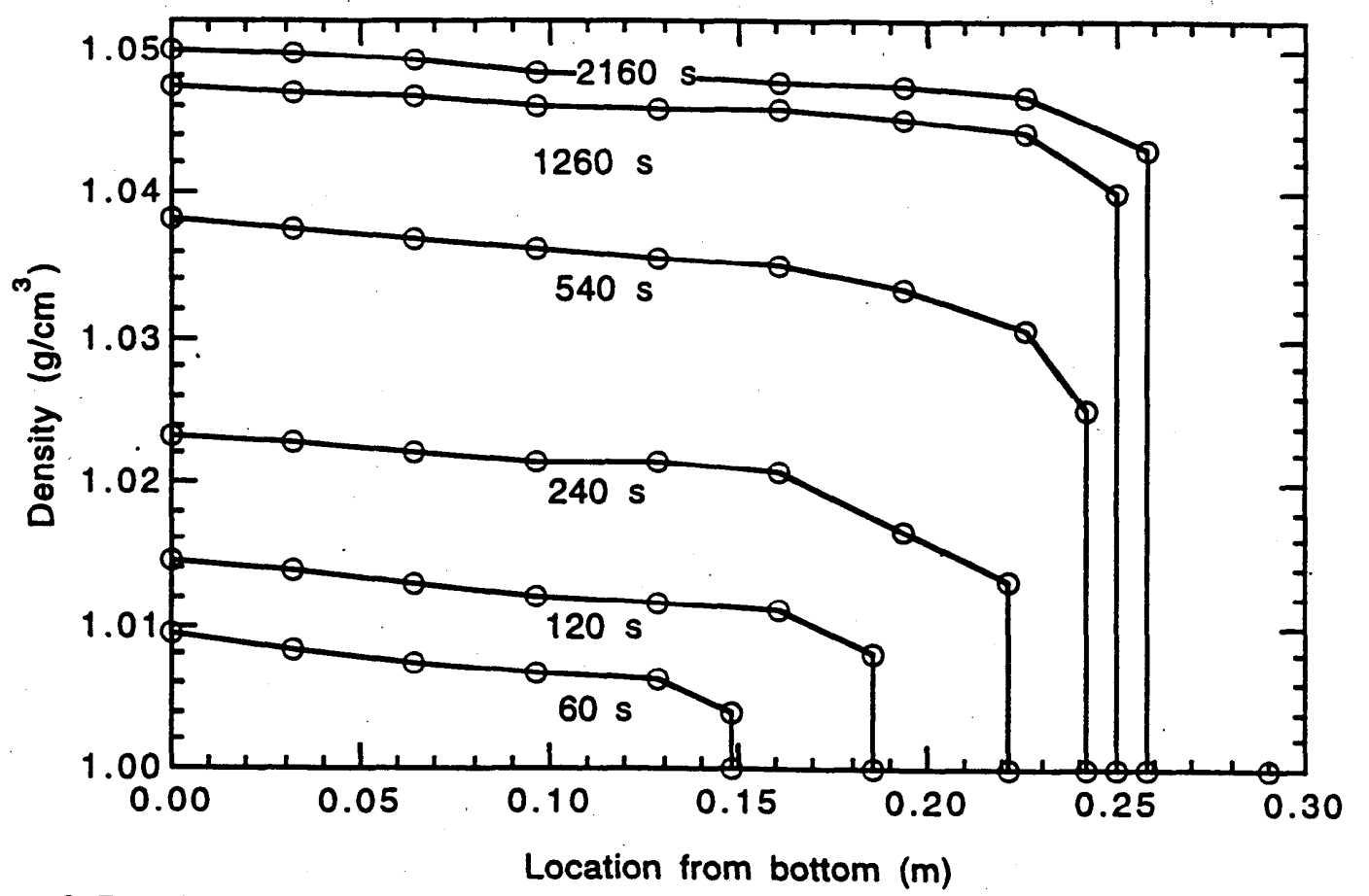

Figure 3 Density distribution for salt water with initial condition of density $1 \mathrm{~g} / \mathrm{cm}^{3}$ at lower compartment and 1.1 at upper compartment

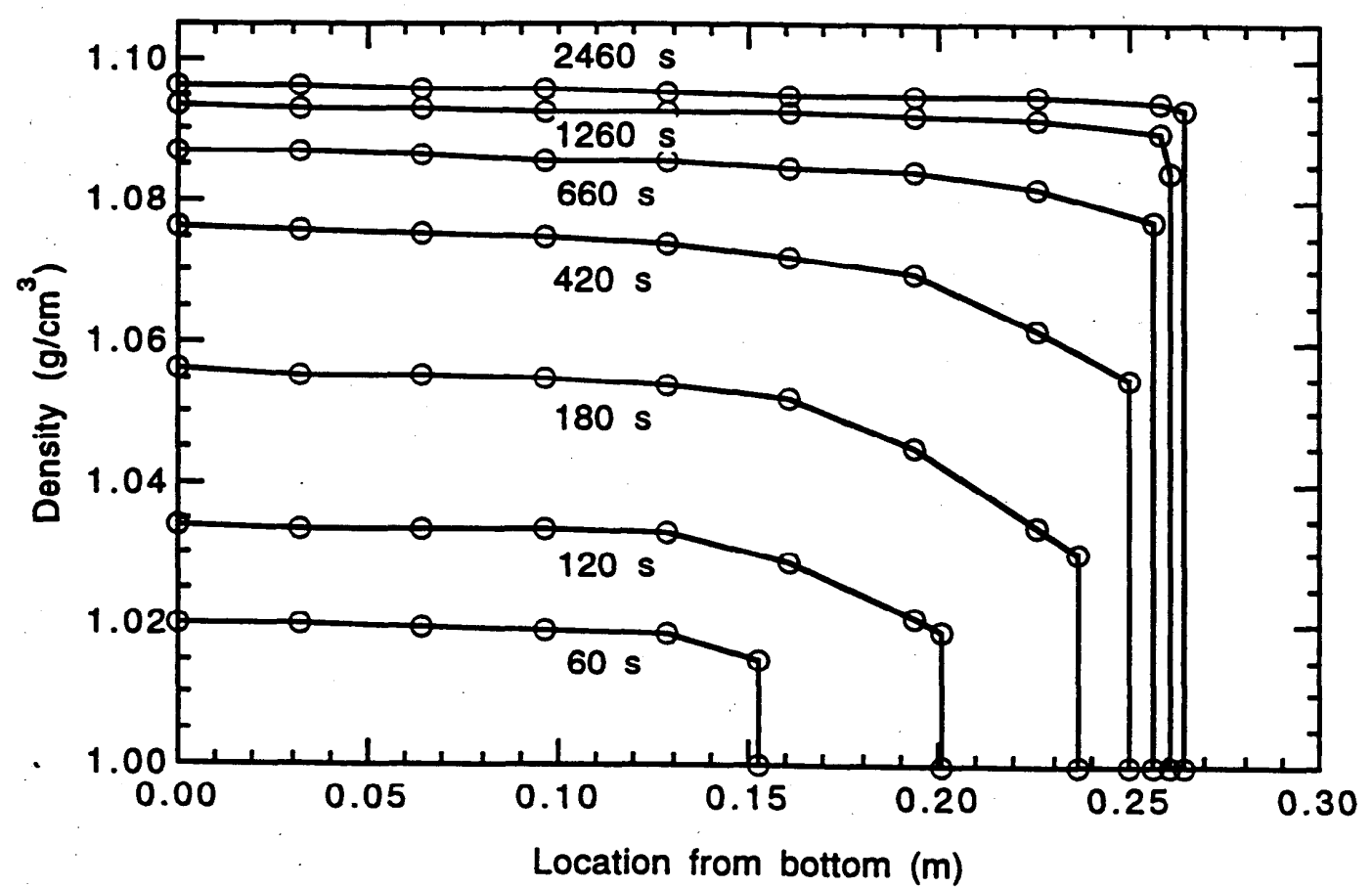

Figure 3 Density distribution for salt water with initial condition of density $1 \mathrm{~g} / \mathrm{cm}^{3}$ at lower compartment and 1.19 at upper compartment 


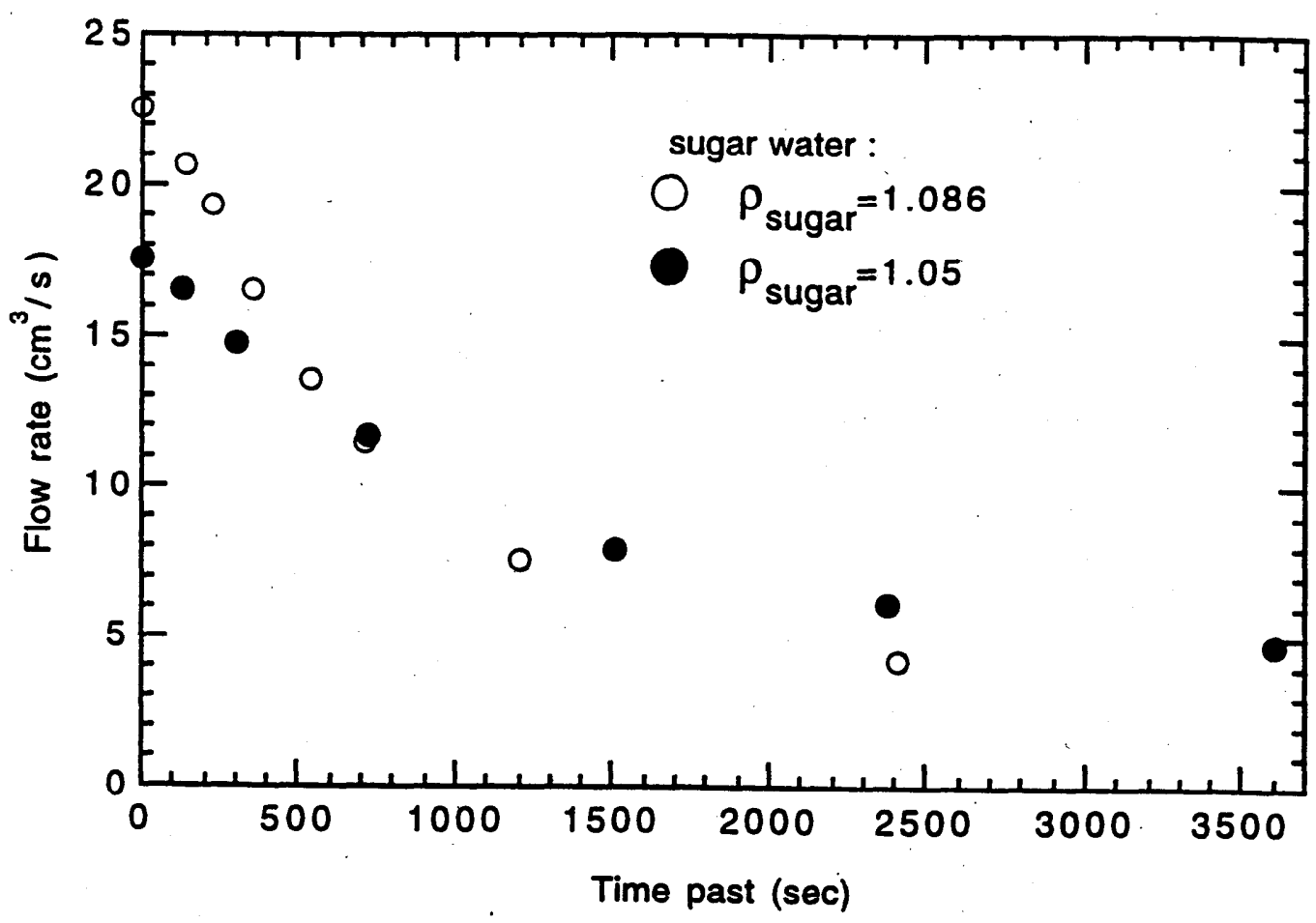

Figure 4 Flow rate of sugar water and pure water calculated from Eq.(6) of Appendix A

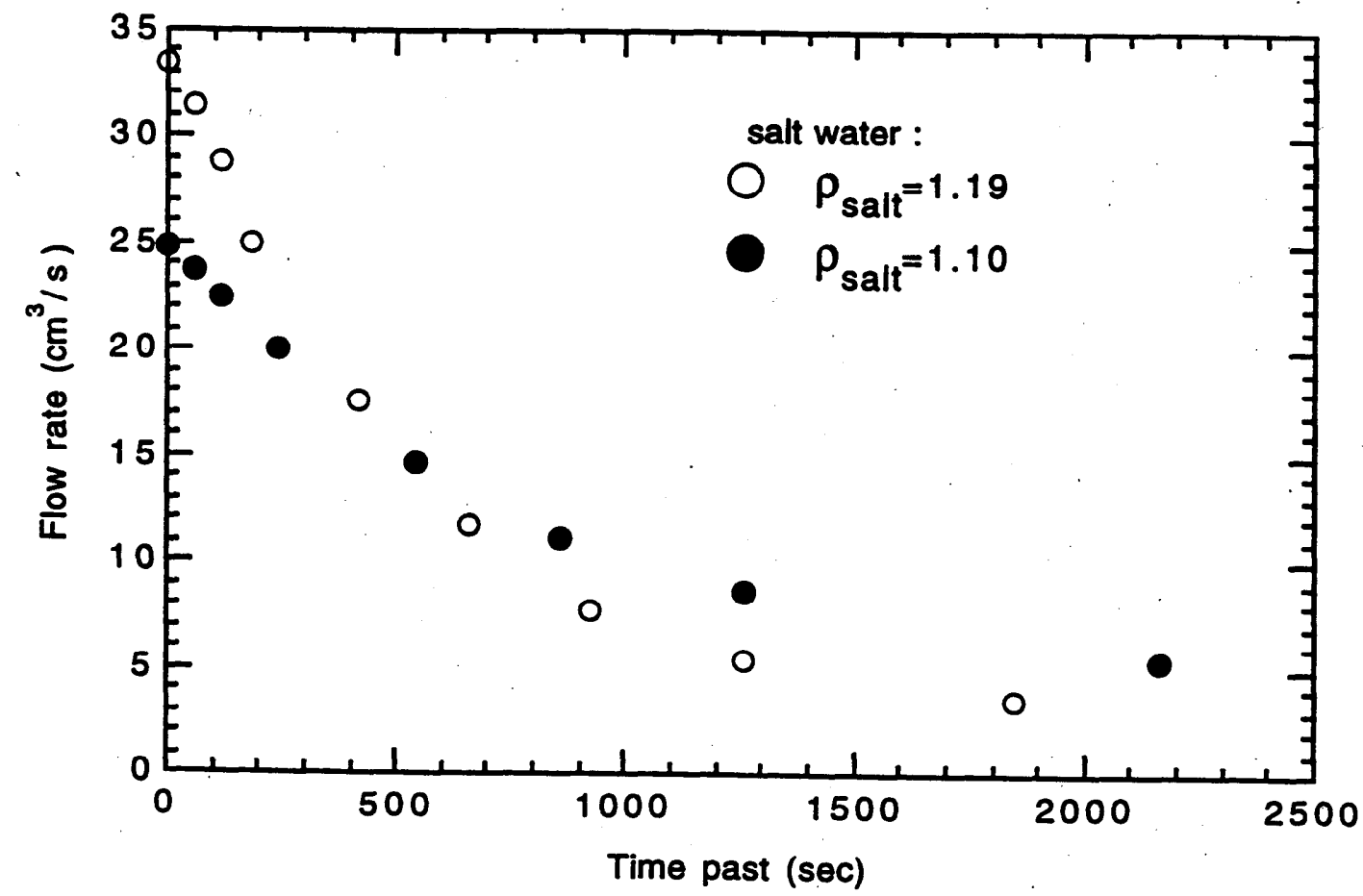

Figure 5 Flow rate of salt water and pure water calculated from Eq.(6) of Appendix A 